NASA Technical Memorandum 101419

\title{
Experimental Determination of Stator Endwall Heat Transfer
}

(NASA-TU-101419) EXP ERIUENTAI DETERMINATION

$\begin{array}{ll}C F & 5 \\ i & p\end{array}$

( $\mathrm{ASA}$ )

CSCI 20D

$\begin{array}{ll}\text { Unclas } \\ 63 / 34 & 0185091\end{array}$

Robert J. Boyle and Louis M. Russell

Lewis Research Center

Cleveland, Ohio

Prepared for the

34th International Gas Turbine and Aeroengine Congress and Exposition sponsored by the American Society of Mechanical Engineers

Toronto, Canada, June 4-8, 1989 


\title{
EXPERIMENTAL DETERMINATION of STATOR ENDWALL HEAT TRANSFER
}

Robert J. Boyle and Louis M. Russell

National Aeronautics and Space Administration

Lewis Research Center

Cleveland, Ohio 44135

\begin{abstract}
Local Stanton numbers were experimentally determined for the endwall surface of a turbine vane passage. A six vane linear cascade having vanes with an axial chord of $13.81 \mathrm{~cm}$ was used. Results were obtained for Reynolds numbers based on inlet velocity and axial chord between 73,000 and 495,000 . The test section was connected to a low pressure exhaust system. Ambient air was drawn into the test section, inlet velocity was controlled up to a maximum of $59.4 \mathrm{~m} / \mathrm{sec}$. The effect of the inlet boundary layer thickness on the endwall heat transfer was determined for a range of test section flow rates. The liquid crystal measurement technique was used to measure heat transfer. Endwall heat transfer was determined by applying electrical power to a foil heater attached to the cascade endwall. The temperature at which the liquid crystal exhibited a specific color was known from a calibration test. Lines showing this specific color were isotherms, and because of uniform heat generation they were also lines of nearly constant heat transfer. Endwall static pressures were measured, along with surveys of total pressure and flow angles at the inlet and exit of the cascade.
\end{abstract}

Nomenclature

$A$ - Area

$C_{p}$ - Specific heat

$c$ - Chord

$c^{*}$ - Critical velocity

$D$ - Diameter of vane leading edge or of cylinder

$d$ - Distance in front of vane or of cylinder

$F$ - Ratio of heat transfer with vane to that without vane

$h$ - Heat transfer coefficient

$I$ - Electrical current

$K$ - Acceleration parameter, $K=\nu / V^{2} d V / d n$

$k$ - Thermal conductivity

$L$ - Pressure loss coefficient, $L=\left(P_{\text {in }}^{\prime}-P_{\text {out }}^{\prime}\right) / Q_{\text {out }}$

$l$ - Length of inlet section

$M^{*}$ - Dimensionless speed, $V / c^{*}$

$n$ - Normal distance

$P$ - Pressure

$Q$ - Dynamic head, $Q=\rho V^{2} / 2$

$q$ - Heat flux

$R$ - Electrical resistance of foil

$R e$ - Reynolds number

$R_{g}$ - Gas constant

$r$ - Recovery factor

$S t$ - Stanton number

$T$ - Temperature

$t$ - Thickness

$V$ - Velocity $x$ - Distance from start of heater

$Y$ - Pressure coefficient, $Y=\left(P_{\text {in }}^{\prime}-P\right) / Q_{\text {in }}$

$\boldsymbol{\gamma}$ - Ratio of specific heats

$\delta$ - Deadband of yellow color

$\theta$ - Normalized temperature, $\theta=\left(T_{l c}-T_{i}\right) /\left(T_{l c}-T_{g}^{\prime}\right)$

$\nu$ - Viscosity

$\rho$ - Density

$\sigma$ - Stefan-Boltzmann constant Subscripts

a - Ambient condition

c - Conduction

$f$ - Heater foil

g - Gas

i - Insulation

in - Cascade inlet

ic - Liquid crystal

loss - Sum of conduction and radiation losses

$M$ - Mylar cover sheet

out - Cascade outlet

$m$ - Measured

out - Cascade outlet

$r$ - Recovery

uc - Uncorrected

$x$ - Axial

- Denotes reference position

- Based on inlet velocity and axial chord

- Based on inlet velocity and leading edge diameter Superscript

- Total conditions 


\section{INTRODUCTION}

Gas turbine cycle efficiency can be increased by raising the turbine inlet temperature or by decreasing the amount of coolant air. To take either of these approaches without adversely affecting the structural durability of the machine requires an accurate understanding of the heat transfer in the turbine. The endwall heat transfer is significant, especially for low aspect ratio turbines where the endwall area exposed to the hot gases approaches in size the blade surface area. The concern with knowing the endwall heat transfer characteristics extends over the entire range of machine sizes. Large turbines are very sensitive to improvements in efficiency. Smaller turbines have greater exposed area per unit of flow, and endwall coolant requirements result in larger decrements in efficiency.

Several investigators have studied the heat transfer for stator endwalls (Refs. 1-7). The stator results were obtained over a wide range of Reynolds numbers. The Reynolds number based on inlet flow velocity and axial chord varied from less than 100,000 to 500,000 . When results from different investigators were compared, it was found that heat transfer distributions varied greatly. For example, the region of maximum heat transfer within the passage varied from near the suction surface to near the pressure surface. While the stators used by the various investigators had about the same amount of flow turning, the vane shapes differed noticeably. In addition to geometric differences a variety of different inlet conditions and experimental approaches were used to obtain the heat transfer results. Shock tubes, hot gas with cooled endwalls, and liquid crystal experimental techniques were all used. The differences among the experiments make it diffcult to confidently determine the reasons for the different endwall heat transfer patterns.

To better understand the factors governing endwall heat transfer a program was undertaken to determine the endwall heat transfer distribution for a turbine stator. Results were obtained for a range of Reynolds numbers, and for three different inlet boundary layers for a single vane geometry. The passage heat transfer distributions were mapped, and detailed measurements were made for the endwall region adjacent to the vane leading edge. The data were obtained in a linear cascade using a liquid crystal measurement technique to determine the endwall heat transfer. In addition to the heat transfer measurements, a number of pressure measurements were made. Endwall static as well as spanwise surveys of total pressure and flow angle were made upstream and downstream of the cascade. The flow rate was controlled to give Reynolds numbers between 73,000 and 495,000 , so as to be in the range of Reynolds numbers used by other investigators.

\section{EXPERIMENTAL FACILITY}

Figure 1 shows an overall view of the test facility. The facility consists of a bellmouth, a constant cross section area inlet duct, the test section proper with the vanes and heated endwall, and an exhaust section. A series of tests were run for each of three different inlets. In the first series the heated test section was adjacent to the bellmouth inlet. The other two series of tests were done with constant cross section inlet area ducts $0.914 \mathrm{~m}(3.0 \mathrm{ft})$, and $1.524 \mathrm{~m}(5.0 \mathrm{ft})$ in length between the bellmouth and the heated section. The duct height was $15.2 \mathrm{~cm}$ (6.0 in.) high and $68.6 \mathrm{~cm}(27.0 \mathrm{in}$.) wide. The maximum test velocity in the duct was $59.4 \mathrm{~m} / \mathrm{sec}$ (195 fps).

Figure 2 shows a closeup view of the heated test section. The vanes had an axial chord of $13.81 \mathrm{~cm}$. The ratio of axial to true chord was 0.718 . The pitch to axial chord ratio was 0.759 . The heated area was $30.5 \mathrm{~cm}$ (12 in.) long and $51.0 \mathrm{~cm}$ (20.1 in.) wide. The heated area began 0.736 axial chords upstream of the test vanes. Three tailboards are shown in figure 2. The two tailboards behind the outer vanes were used to obtain periodicity at the exit of each of the passages. Two adjustable flow control vanes are shown in figure 2. These two vanes were used to control the flow to ensure upstream periodicity. There were six turbine vanes in the cascade, and the center passage was used as the test passage. Three diferent lids were used for the test section. One lid had pressure taps, and was used to map the endwall flow field. The second lid was made of clear acrylic, and was used during the heat transfer tests. The third lid had an open area downstream of the cascade, and was used for the exit surveys. During the exit survey tests an actuator table was secured to the top of the lid.

The vane profile shapes were scaled from those used in the heat transfer tests of Blair (Ref. 3). The passage flow characteristics of the vanes used by Blair were measured by Bailey (Ref. 8). Both of these investigations were done in a single passage wind tunnel. The vanes used in the present investigation were scaled down from the coordinates given in reference 8 . The vanes were made of wood, but the two vanes forming the test passage had brass bases. Cooling passages were formed into the brass bases. This was done to insure that the heat generated underneath the vanes could be removed, so that excessive temperatures underneath the vanes would not damage the liquid crystal sheet. Thermocouples were attached to the bases, and routed out through the top of the vane. No active cooling was necessary, because the fin effect of the base was sufficient to remove the heat generated underneath the vane. After the tests were completed some deterioration of the liquid sheet was noted underneath the all wood guard vanes.

Figure 3 shows the assembly of the liquid crystal/heater composite. A thin sheet of metallic foil, $0.025 \mathrm{~mm}$ ( $1 \mathrm{mil}$ ), was electrically heated to provide the heat source. Inconel was used because of its high electrical resistivity and low thermal coefficient of resistivity. The Inconel foil was bonded to copper bus bars. The heat flux was determined from the sheet's resistivity and the electrical current. The voltage drop at the bus bars was measured to assure that their was no significant heat generated at the bus bar-foil junctions. The foil heater was attached to the floor of the test section using double-sided tape. The floor was $1.91 \mathrm{~cm}$ thick, and made of 
Bakelite to minimize heat loss. The composite liquid crystal sheet was attached to the foil heater using double-sided tape. The liquid crystal composite consisted of an opaque seal coat, the sheet of liquid crystal material, and a transparent Mylar outer cover. The thickness of the composite sheet was 0.20 $\mathrm{mm}$, of which $0.11 \mathrm{~mm}$ was the Mylar cover sheet. The liquid crystal sheet was the cholesteric type which changed color with temperature. The highest sensitivity to temperature was obtained at a yellow color. The temperature at which the liquid crystal sheet exhibited this color was $40.9^{\circ} \mathrm{C}$ $\left(105.6^{\circ} \mathrm{F}\right)$. Changes in temperature of $\pm 0.06^{\circ} \mathrm{C}$ caused the yellow color to disappear. A uniformly spaced grid was inked on to the Mylar surface. Black ink was used.

\section{INSTRUMENTATION}

The electrical current was measured using the voltage drop across a calibrated shunt. Chromel-constantan (Type E) thermocouples were used to measure inlet gas total temperature, the temperature of the base of the two vanes forming the test passage, as well as temperatures on the outer surface of the Bakelite floor.

The top of the inlet section contained access holes into which total pressure probes were inserted. Spanwise traverses were made to insure uniformity of total pressure outside of the endwall boundary layers. The same access holes were subsequently used with drilled plugs to measure static pressures. Having uniformity in the pitchwise direction in static and total pressures resulted in uniform inlet flow.

Endwall static pressures were recorded using a Scanivalve measuring system. Approximately 40 static taps were used to measure the endwall pressure distribution. Boundary layer measurements were made upstream and downstream of the cascade using three-hole total-angle probes. A three-hole probe with a thickness of $0.51 \mathrm{~mm}$ (0.020 in.) was used for the boundary layer probe. In order to make accurate pressure surveys over a wide range of flow velocities, parallel measurements were made using transducers with different ranges. The transducers full range output varied between \pm 0.6895 and $\pm 34.47 \mathrm{kPa}$ (0.1 to 5.0 psid).

The position of the yellow isotherm was recorded using photographic slides. To obtain full photographic coverage of the passage, as well as both leading edges, photographs were taken with up to three cameras simultaneously. Contour maps of the endwall heat transfer were obtained by plotting the digitized results from a number of different slides. The isotherm was digitized by projecting the slide onto a digitizing tablet. The position on the endwall was determined by digitizing both the yellow line and grid coordinates. In some locations, such as around the leading edge, there were very steep gradients in isotherms. Some photographs did not have good contrast between the grid lines and the background color. The digitizing of these data was more tedious than necessary. In retrospect, it would be better to have inked the grid in a color that contrasted with both the yellow line and with the black background.
All pressure transducer signals, voltage measurements, and thermocouple readings were continuously recorded on a three second update cycle. When the photographs were made, a simultaneous record of these signals was also recorded. The photographs were time stamped as part of the recording process.

\section{ANALYSIS of DATA}

The Stanton number is given by

$$
S t=\frac{q_{\text {net }}}{(\rho V)_{\text {in }} C_{p}\left(T_{M}-T_{r}\right)}
$$

The heat flux was obtained from

$$
q_{\mathrm{net}}=\frac{I^{2} R}{A_{l}}-q_{\mathrm{loss}}
$$

The first term, $I^{2} R / A_{f}$, is the heat flux generated by the electrical power applied to the foil heater. The $q_{\text {loss }}$ term represents the corrections to the measured heat transfer due to losses. There were heat losses due to conduction through the Bakelite insulation material, and radiation from the endwall surface. In addition there was a correction to the heat transfer due to the temperature drop across the Mylar cover sheet. Appendix A gives a more detailed discussion of the corrections made to the measured heat flux, as well as a discussion of the importance of the individual losses over the range of flow conditions.

In the presentation of the results the recovery factor was taken as 1.0. Therefore, $T_{r}=T_{o}^{\prime}$. When the temperature difference used in the Stanton number definition is the difference between the surface and gas total temperatures, the defined heat transfer coefficient depends on the inlet velocity, and not the local velocity. The effect of a variable recovery temperature on the Stanton number is proportional to the ratio of the temperature difference with the actual recovery temperature, $\Delta T_{1}$, to the temperature difference with a recovery factor of one, $\Delta T_{2}$. This ratio is given by

$$
\frac{\Delta T_{1}}{\Delta T_{2}}=\frac{T_{M} / T_{g}^{\prime}-T_{r} / T_{g}^{\prime}}{T_{M} / T_{g}^{\prime}-1.0}
$$

The ratio $T_{r} / T_{g}^{\prime}$ is given by

$$
\frac{T_{r}}{T_{g}^{\prime}}=\frac{T}{T_{g}^{\prime}}(1-r)+r
$$

The ratio $T / T_{g}^{\prime}$ is given by

$$
\frac{T}{T_{g}^{\prime}}=1-\frac{(\gamma-1)}{(\gamma+1)} M^{* 2}
$$

Where $M^{*}=V / c^{*}$, and the local velocity can be found from the pressure coefficient, $Y$ using the relationship $Y=$ $\rho V^{2} / \rho_{\text {in }} V_{\text {in }}^{2}$. Since the inlet velocities are low, $\rho_{\text {in }}=\rho^{\prime}$. The local density is found from

$$
\frac{\rho^{\prime}}{\rho} \cong 1+\frac{M^{\star 2}}{\gamma+1}
$$


Since $c^{* 2}=2 \gamma R_{g} T_{g}^{\prime} /(\gamma+1)$, the ratio of the two temperature differences becomes

$$
\frac{\Delta T_{1}}{\Delta T_{2}} \cong 1+\frac{(1-r)}{\left(T_{M} / T_{g}^{\prime}-1\right)} \frac{(\gamma-1)}{2 \gamma} \frac{Y V_{\mathrm{in}}^{2}}{R_{g} T_{g}^{\prime}}\left[1+\frac{Y V_{\mathrm{in}}^{2}}{2 \gamma R_{g} T_{g}^{\prime}}\right]
$$

The flow is turbulent so that the recovery factor, $r$, is 0.89 . The second term inside the brackets represents the effect due to compressibility. The two terms were evaluated for the maximum values of $Y$, and $V_{\text {in }}$. The ratio of the two temperature differences was within $15 \%$. The actual heat transfer would be less than the presented one by at most this amount. Since the experimental data presents a contour plot of the pressure coefficient, the heat transfer results given in this paper can be compared with results using a locally varying recovery temperature, if necessary.

The uncertainty in the Stanton number contours comes from two sources. There is the uncertainty in the individual measurements used to determine the Stanton number, and there is the uncertainty in the position of the Stanton number contour. The uncertainty analysis for the Stanton number measurement is conveniently done for the uncorrected Stanton number. The uncorrected Stanton number is given by

$$
S t_{\mathrm{uc}}=\frac{\Gamma^{2} R}{A_{f}(\rho V)_{\mathrm{in}} C_{p} \Delta T}
$$

The temperature difference is $\Delta T=T_{l c}-T_{g}^{\prime}$. In terms of measured quantities this becomes

$$
S t_{u c}=\frac{I^{2} R}{\sqrt{\Delta P} \Delta T} \frac{\sqrt{T / P}}{A_{f}} \frac{\sqrt{R_{o}}}{C_{p} \sqrt{2}}
$$

The pressure difference, $\Delta P$, is $P^{\prime}-P$ at the inlet, and is a single measurement. The absolute quantities $T, P$, and $A$ can be measured precisely, and do not significantly contribute to the Stanton number uncertainty. For the remaining terms

$$
\frac{d S t_{u c}}{S t_{u c}}=\frac{2 d I}{I}-\frac{d \Delta P}{2 \Delta P}-\frac{d \Delta T}{\Delta T}+\frac{d R}{R}
$$

Since the uncertainty is obtained from the square root of the sum of the individual uncertainties squared, for a uniform relative uncertainty, the uncertainty in the electric current, I, dominates the uncertainty in the Stanton number. Prior to the first of a series of tests the signal for the current was measured. The zero value was used to adjust each of the heat transfer measurements. In addition, the current signal was integrated over a 10 second interval to average out any high frequency noise. Based on an analysis of the uncertainty of the individual measurements, the uncertainty in the Stanton number was estimated to be $10 \%$ or less.

The uncertainty in the location of the Stanton number is largely determined by the gradient of the Stanton number. There is a small, $\Omega 0.06 \mathrm{C}$, temperature range over which the liquid crystal appears yellow. This temperature range corresponds to a range of Stanton numbers. The variation in the position of the yellow line is given by

$$
n-n_{0}=\frac{S t-S t_{0}}{d S t / d n}
$$

The subscript, $u c$, has been dropped for simplicity. Only $T_{l c}$ is a function of position. At the point $n_{0}$

$$
\frac{d S t_{0}}{d n}=\frac{q_{\text {net }}}{\rho V_{\text {in }} C_{p} \Delta T_{0}^{2}} \frac{d T_{0}}{d n}
$$

$\Delta T_{0}$ is the temperature difference between the liquid crystal sheet and the gas. The variation in position can be expressed in terms of temperatures as

$$
n-n_{0}=\left(\frac{1}{\Delta T}-\frac{1}{\Delta T_{0}}\right) \Delta T_{0}^{2} \frac{d n}{d T_{0}}
$$

The uncertainty for the specified (yellow) color is $\delta T=$ $\Delta T-\Delta T_{0}$ and was estimated to be $0.06 \mathrm{C}$.

Since $\Delta T_{0} d n / d T_{0}=S t_{0} d n / d S t_{0}$, the variation in position can be expressed as

$$
\frac{n-n_{0}}{c_{x}}=\frac{-\sqrt{2} \delta T}{\Delta T} \frac{S t_{0}}{c_{x}} \frac{d n}{d S t_{0}}
$$

The $\sqrt{2}$ is included because the reference position, $n_{0}$, is also subject to uncertainty. For the test conditions employed, a variation of $10 \%$ in the Stanton number over a normal distance equal to $10 \%$ of axial chord results in an uncertainty in position of less than $1 \%$.

\section{EXPERIMENTAL RESULTS}

\section{Flow measurements}

Inlet boundary layer surveys were made for the two series inlets. At an inlet velocity of $15.2 \mathrm{~m} / \mathrm{sec}$. the displacement thickness for the short inlet, $l / c_{x}=6.4$, was found to be $2.65 \mathrm{~mm}$, and for the longer inlet, $l / c_{x}=11$, the displacement thickness was $3.30 \mathrm{~mm}$. These values were approximately consistent with calculated values of boundary layer thickness assuming the boundary layer started at the beginning of the constant area duct. Turbulence intensity measurements were made using hot wire measurements when the shorter of the two inlets was in place. The midspan turbulence intensity was measured to be about $2 \%$ at a location just upstream of the heated section.

Figure 4 shows a contour plot of the endwall static pressures. This figure shows the pressure coefficient, $Y$, contours. $\mathrm{Y}$ is defined so that upstream of the vane row $\mathrm{Y}$ is approximately 1.0. The contour plot shows that the exit dynamic head is 10 times that of the inlet dynamic head. The results shown are for an inlet velocity of $53 \mathrm{~m} / \mathrm{sec}$. There was no definite change in the endwall static pressure distribution as the inlet velocity was decreased. Since the dynamic head increases as the velocity squared, the precision of the measurements was best at the highest velocity.

\section{Heat transfer results}

The primary heat transfer results consist of Stanton number contour plots over the entire endwall region at different Reynolds numbers for the three different inlet boundary 
layers. The liquid crystal measurement technique allows for detailed measurement in regions of high heat transfer gradients. The heat transfer in the leading edge region of the vane is discussed in detail. The heat transfer upstream of the vanes is compared with expected results for flow over a flat plate with an unheated starting length.

Overall endwall heat transfer results. Figures 5, 6, and 7 show lines of constant Stanton numbers for the endwall region for the three different inlet sections. Each figure has results for a range of Reynolds numbers. The Reynolds number is based on the inlet velocity and axial chord. The trends in the data are very similar for the different inlet boundary layers. The difference in the average endwall Stanton number for the different Reynolds numbers is close to what is expected for turbulent flow. For a flat plate the Stanton number varies as the Reynolds number to the -0.2 power. $A$ factor of 6 increase in Reynolds number would decrease the Stanton number for a flat plate by $43 \%$. These figures show similar heat transfer near the leading edges for the two vanes that define the test passage.

There is a marked change in the heat transfer pattern with changes in Reynolds number. At low Reynolds numbers the Stanton number contours tend to follow inviscid streamlines, and then deflect towards the suction surface. For low Reynolds numbers the secondary flow from the pressure surface towards the suction surface occurs to a greater degree. Also, the acceleration parameter, $\mathrm{K}$, becomes more significant at low Reynolds numbers. When variations in density are neglected, the acceleration parameter is given as

$$
K \cong \frac{1}{2 R e_{1} Y^{3 / 2}} \frac{d Y}{d\left(n / c_{x}\right)}
$$

When the acceleration parameter exceedes $3 \times 10^{-6}$, the boundary layer relaminarizes, thus lowering the Stanton number. The pressure coefficient, $Y$, and its gradient can be determined at different locations within the passage from the data in figure 4. For pressure coefficients between 4.0 and 9.0 the term $d Y / d\left(n / c_{x}\right) / Y^{3 / 2}$ has a value of approximately 1.1. Using this value indicates that relaminarization will only occur for Reynolds numbers less than about 165,000 . The relaminarization of the endwall flow may be the reason that, at low Reynolds numbers, the Stanton number does not respond to the increased velocity in the throat region to the same extent that it does at high Reynolds numbers. At high Reynolds numbers the acceleration parameter is less, and the Stanton number contours reflect the influence of the freestream velocity. Consequently, the highest Stanton numbers are in regions of highest freestream velocity. The Stanton number contours are similar in shape to the pressure contours shown in figure 4. The Stanton numbers given in figures 5,6 , and 7 are based on an inlet reference velocity. Consequently, changes in Stanton number correspond to changes in heat transfer coefficient. For turbulent flow $h \propto(\rho V)^{.8}$. To a first order approximation $h \propto Y^{.4}$. At high Reynolds numbers the experimental data show that the ratio of the Stanton number from just upstream of the vane to the local value within the passage correlates reasonably well with the value of $Y^{.4}$ from figure 4 .

Leading edge region heat transfer. Figure 8 shows the endwall heat transfer in the region of the vane leading edge. The augmentation factor, $F$, is given as a function of the distance in front of the vane. The augmentation factor is the ratio of the local Stanton number to the local value when there are no vanes. No tests were run without vanes. The denominator used to form the augmentation factor was determined from the experimental heat transfer at the leading edge, but at a pitchwise location midway between the vanes. The results shown in the three parts of figure 8 are for the average of the two vanes. To improve spacial resolution near the leading edge one camera's field of view was concentrated in this area. Each part of figure 8 is for a different inlet, and each part contains results for different Reynolds numbers. The Reynolds numbers given in the figure are based on the diameter of the vane leading edge circle. The flow conditions are actually the same as for the figures showing the passage Stanton number contours. The augmentation increases as the distance in front of the vane decreases. Figure 9 shows the heat transfer augmentation in front of a cylinder presented by a number of investigators (Ref. 9-12). The data show considerable variation among the different sources. From a design standpoint it is not clear which results should be used to predict endwall heat transfer near a cylinder. This question also applies to the leading edge region of a turbine vane or rotor blade. The data in figure 8 indicate that the condition of the endwall boundary layer may affect the degree of augmentation caused by a cylinder or blade. The data in figure $8(a)$ show the highest augmentation for the lowest Reynolds number results. It will be shown that only for the lowest Reynolds number did the flow remain laminar up to the vane leading edge, even with no inlet section. The highest augmentations shown in figure 9 are for low Reynolds number cases. This may have been the result of the flow being laminar up to the region of the cylinder. The experimental results for the heat transfer in the leading edge region are in good agreement with the data of Goldstein and Spores (Ref. 13). The data of this reference are for heat transfer measurements on the endwall of a rotor configuration. Their data indicate a turbulent boundary layer upstream of the rotor blade. The data of Goldstein and Spores show peak endwall heat transfer augmentation in front of the leading edge to be somewhat in excess of 3.25. The data shown in figure 8 shows that an extrapolation of the augmentation to a point at the leading edge gives nearly the same augmentation.

Unheated starting length. It was expected that the heat transfer upstream of the leading edge would correlate well with the heat transfer for flow over a flat plate with an unheated starting length. Because of the vane blockage it was not known how far upstream of the leading edge the experimental data would diverge from the flat plate correlation. Figure 10 compares the experimental data with the correlation. Figure $10(\mathrm{a})$ is for the case with no inlet (where the bellmouth entrance is adjacent to the heated section). 
The correlation given in this figure is for laminar flow. Only at the lowest Reynolds number do the data agree with the laminar correlation. At higher flow rates the heat transfer data indicate transition even before the leading edge plane. The boundary layer is turbulent before the heated section is reached.

Figure 10b shows the results for the two different inlet sections. The inlets are sufficiently long that the flow is turbulent before the heated section is reached. The correlation for the long inlet is only slightly lower than the correlation for the short inlet. Also shown in this figure is the heat transfer prediction using the STAN5 finite difference code of Crawford and Kays (ref. 14). The experimental data were measured along a line midway between the vanes. The experimental data are somewhat higher than the predicted heat transfer. This may be due to conduction loss in the axial direction at the start of the the heated section. A two dimensional conduction analysis was done for the region close to the start of the heated test section. The analysis showed that at distance of $x / c_{x}=.1$ at a Reynolds number of 76,000 the Stanton number would be reduced $20 \%$. This is the result of axial heat flow to the unheated section upstream of the heated section. When the distance from the start of the heated section was increased to $x / c_{x}=0.5$, the Stanton number would be reduced by less than $5 \%$ as the result of including the effects of axial conduction. As the Reynolds number is increased the effect of axial conduction decreases. At a Reynolds number of 150,000 and $x / c_{x}=0.1$ the decrease in Stanton number due to axial conduction was $10 \%$. The solid symbols in figure $10 \mathrm{~b}$ show the Stanton number when the effect of axial conduction is included.

At $x / c_{x} \approx 0.3$ the experimental data is significantly higher than the predictions at low Reynolds numbers. This is probably the result of underpredicting the heat loss through the Bakelite insulation in the normal direction. The thermocouples on the exterior of the insulation were placed opposite the test passage. The same exterior temperature was used to correct the Stanton numbers upstream of the vane. Effectively this assumed the same external natural convection heat transfer cofficient. Since the external geometry was different in this region due to the supporting structure, this was a bad assumption. Calculations were done to determine the correction in Stanton number when the exterior insulation and ambient temperatures were equal. The results showed changes in Stanton number more than enough to account for the differences between the prediction and experimental data. Since both axial and normal conduction are important at low Reynolds numbers, a lower conductivity material would have to be used to reduce heat loss to a negligible level. Just increasing insulation thickness would allow for more axial conduction. Alternatively, a complete map of the external and upstream boundary temperatures could be used to properly account for heat losses at low Reynolds numbers. Near the leading edge the experimental and predicted Stanton numbers are in good agreement over a wide range of Reynolds numbers. This indicates that the corrections applied to the measured heat flux were appropriate when the external insulation temperatures were known. As discussed in Appendix A, the corrections to the heat flux were substantial for some test conditions. At the combination of lowest heat flux and Reynolds number the corrected Stanton number was approximately $20 \%$ less than the uncorrected value. This was the result of heat loss through the Bakelite insulation and radiation to the surroundings. At the combination of highest heat tlux and Reynolds number the corrected Stanton number was approximately $30 \%$ greater than the uncorrected value. This was primarily caused by temperature drop across the cover sheet used to seal the liquid crystal.

\section{Exit surveys}

Figure 11 shows the results of a pitchwise total pressure survey. The survey was made 0.11 axial chord downstream of the vane trailing edge. This was fairly close to the trailing edge of the vane. This survey was made at midspan, so that endwall effects would be at a minimum. The high total pressure loss wake regions are clearly shown. Between the wakes the loss level is nearly zero. Shown along the abscissa of this figure are three pitchwise locations at which spanwise boundary layer surveys were made.

Figure 12 shows the results of spanwise surveys made downstream of the vane near the suction surface. This is the leftmost location given in figure 11. Figure 12(a) shows the total pressure loss coefficient as a function of the distance from the endwall, and figure 12(b) shows the flow angle that was measured simultaneously with the total pressure. Results are given for different Reynolds numbers. While the probe was near the suction surface, it was outside of the midspan wake region. The distributions of loss as well as flow angle were strongly influenced by Reynolds number. Data were taken over a range of Reynolds numbers, and for convenience they have been grouped into three ranges. The data in the lowest Reynolds number range differ markedly from the data in the other two ranges. The two higher Reynolds number ranges show very similar behavior in terms of both loss and flow angle turning. Only in the lowest Reynolds number range is relaminarization of the flow likely to have occurred. For this range of flows the boundary layer adjacent to the wall is thinner, and the flow is overturned toward the suction surface. While the endwall boundary layer is thinner, the loss at $2 \mathrm{~cm}$ from the endwall is greater for the lowest Reynolds number range. This loss is associated with the vortices formed within the passage.

Figure 13 shows the same data as figure 12 , but for a pitchwise location midway between the suction and pressure surfaces. The results show that Reynolds number effect is still present. The effect is much less pronounced, and is primarily evidenced by differences in the flow angle adjacent to the wall. Figure 14 shows the same data as figure 12 , but for a location near the pressure surface. At this pitchwise location there is no difference among the results for the different Reynolds numbers. 


\section{CONCLUSIONS}

The results of the experimental investigation showed that the heat transfer distribution on the endwall of a turbine stator vane cascade was strongly influenced by the flow through the cascade. At low Reynolds numbers the heat transfer contours are somewhat aligned with the inviscid flow streamlines. At high Reynolds numbers the heat transfer distributions are significantly different. At high Reynolds numbers the local endwall heat transfer coefficient correlates well with the local freestream velocity.

The pattern of the Stanton number contour lines was noticeably affected by changes in Reynolds number. The pattern of the Stanton number contour lines was not affected by changes in the thickness of the incoming boundary layer. There was a change in the level of the Stanton number with changes in the thickness of this boundary layer. This change was of the same magnitude as would be expected due to the thicker inlet boundary layers. This was expected upstream of the vane leading edge. The same change was seen within the vane passage as well.

Spanwise total pressure loss and flow angle surveys were made at different pitchwise locations. These surveys were done at a distance of 0.11 axial chord behind the vane trailing edge. Near the vane suction surface the spanwise distribution of both loss and flow angle was strongly influenced by Reynolds number. At the midpitch location the Reynolds number effect was still noticeable, but much less pronounced. There was no noticeable Reynolds number effect near the pressure surface. The results of the spanwise surveys indicated that relaminarization of the turbulent endwall boundary layers significantly affected the boundary layer developement within the passage. The survey data support the inference that flow relaminarization significantly affects the pattern of the endwall Stanton number contours.

\section{REF ERENCES}

1. Dunn, M.G., and Hause, A., "Measurement of Heat Flux and Pressure in a Turbine Stage”, ASME J. of Engineering for Power, Vol 104, No. 1, Jan 1982.

2. Dunn, M.G., Martin, H.L., and Stanek, M.J., "HeatFlux and Pressure Measurements and Comparison With Predictions for a Low Aspect Ratio Turbine Stage”, ASME Paper 86-GT-79, 1986.

3. Blair, M.F., "An Experimental Study of Heat Transfer and Film Cooling on Large-Scale Turbine Endwalls", ASME Journal of Heat Transfer, Vol. 96, 1974.
4. Brooks, A.J., Colbourne, D.E., Wedlake, E.T., Oldfield, M.L.G., Schultz, D.I., Jones, T.V., and Loftus, P.J., "The Isentropic Light Piston Annular Cascade Facility at RA Pyestock," in AGARD Pub. No. 390, "Heat Transfer and Cooling in Gas Turbines," 1985.

5. Georgiou, D.P., Godard, M., and Richards, B.E., "Experimental Study of the Iso-Heat-Transfer-Rate Lines on the End-Wall of a Turbine Cascade", ASME Paper 79-GT-20, 1979.

6. York, R.E., Hylton, L.D., and Mihelc, M.S., "Experimental Endwall Heat Transfer and Aerodynamics in a Linear Vane Cascade.", J. Engr. for Gas Turbines and Power, Vol. 106, 1984, pp 159-167

7. Hippensteele, S.A., and Russell, L.M., “High Resolution Liquid Crystal Heat Transfer Measurements on the Endwall of a Turbine Passage with Variations in Reynolds Number"., in Proceedings of the 1988 National Heat Transfer Conference. ASME Pub. HTD-96, Vol. 3 pp 443-453, 1988.

8. Bailey, D.A., "Study of Mean- and Turbulent Velocity Fields in a Large-Scale Turbine-Vane Passage", NASA CR-3067, 1979.

9. Hinckel, J. N., and Nagamatsu, H.T., "Heat Transfer in the Stagnation Region of the Junction of a Circular Cylinder Perpendicular to a Flat Plate”., Int. J. Heat Mass Transfer. Vol. 29 No. 7 pp 999-1005, 1986.

10. Goldstein, R.J., Chyu, M.K., and Hain, R.C., "Measurement of Local Mass Transfer on a Surface in the Region of the Base of a Protruding Cylinder with a Computer-Controlled Data Acquisition System", Int. J. Heat Mass Transfer. Vol. 28, No. 5, pp 977-985, 1985

11. Ireland, P.T., and Jones, T.V., "Detailed Measurements of Heat Transfer on and Around a Pedestal in Fully Developed Passage Flown. Proceedings of the 8 th Int. Heat Transfer Conference, San Francisco, CA. Vol. 3, Hemisphere Pub. Corp., pp 975-980, 1986.

12. Akino, N., Kunugi, T., Ichimiya K., Mitsushiro, K., and Ueda, M., "Improved Liquid Crystal Thermometry Excluding Human Color Sensation, Part II-Application to the Determination of Wall Temperature Distributions", in Pressure and Temperature Measurements., ASME Pub. HTD vol. 58 , pp 57-62, 1986. 
13. Goldstein, R.J., and Spores, R.A., "Turbulent Transport on the Region Between Adjacent Turbine Blades". ASME Journal of Heat Transfer, Vol. 110, No. 4, Nov. 1988, pp 862-869.

14. Crawford, M.E., and Kays, W.M., "STAN5- A Program for Numerical Computation of Two-Dimensional Internal and External Boundary Layer Flows", NASA CR 2742, 1976.

\section{APPENDIX A}

Corrections to measured heat flux

The measured heat flux is given by

$$
q_{\mathrm{m}}=I^{2} R / A_{f}
$$

The net heat flux is given by

$$
q_{\mathrm{net}}=q_{\mathrm{m}}-q_{\mathrm{c}}-q_{\mathrm{rad}}
$$

The actual heat transfer coefficient is given by

$$
h=q_{\text {net }} /\left(T_{M}-T_{r}\right)
$$

The conduction through the Mylar cover of the insulation is given by

$$
q_{M}=k_{M}\left(T_{M}-T_{l c}\right) / t_{M}
$$

The heat flux through the Mylar cover sheet equals the net heat flux. Therefore

$$
k_{M}\left(T_{M}-T_{i c}\right) / t_{M}=h\left(T_{M}-T_{r}\right)
$$

The heat flux through the Bakelite insulation material is given by

$$
q_{c}=k_{i}\left(T_{i c}-T_{i}\right) / t_{i}
$$

The value of $T_{i}$ was obtained by interpolating the measured temperatures on the outside of the insulation. Since there was a thermal resistance between the insulation and ambient, this temperature was higher than the ambient temperature. The radiant heat flux is given by

$$
q_{\mathrm{rad}}=\sigma\left(T_{M}^{4}-T_{a}^{4}\right)
$$

While the Mylar cover sheet is transparent to visible light, it is opaque and nonreflective in the infrared region of the test temperatures. The heat balance can be rearranged to give

$$
k_{M}\left(T_{M}-T_{l c}\right) / t_{M}=I^{2} R / A_{f}-k_{i}\left(T_{l c}-T_{i}\right) / t_{i}-\sigma\left(T_{M}^{4}-T_{a}^{4}\right)
$$

The recovery factor was taken as one, so that $T_{r}=T_{a}$. The above equation is then solved to determine the outer temperature of the Mylar cover sheet, $T_{M}$. Once $T_{M}$ is determined the net heat flux can be calculated. The heat transfer coefficient is determined from the net heat flux. The uncorrected heat transfer coefficient, $h_{u c}$, is found from

$$
h_{u c}=\frac{I^{2} R}{A_{f}\left(T_{l c}-T_{r}\right)}
$$

Once the corrected and uncorrected heat transfer coefficients have been determined, the corresponding corrected and uncorrected Stanton numbers can be calculated. Figure A1 shows the corrected Stanton number versus the test Reynolds number for a range of uncorrected Stanton numbers. Data are shown for two values of the normalized outer insulation temperature, $\theta_{i}$. The temperature used to correct the experimental data came from thermocouples on the outside of the insulation. The normalized temperature was within the range of $\theta$ values shown on the figure. This figure shows that at the midrange of both the Reynolds number and of the uncorrected Stanton number the correction to the Stanton number is small. However, at the combination of low Reynolds number and low Stanton number the correction is substantial, being about $25 \%$ for the combination of lowest Reynolds and Stanton numbers. At these conditions heat loss through the Bakelite insulation as well as the radiant energy loss dominate the correction. Doubling the thickness of the Bakelite insulation would not halve the conduction loss. As the insulation becomes thicker there would be an increase in thermal conduction within the insulation. Also, at the combination of high Reynolds number and high Stanton number the correction is again substantial, again being about $25 \%$. At these conditions the heat flux to the air is very high, and there is a substantial temperature difference across the Mylar cover sheet. 


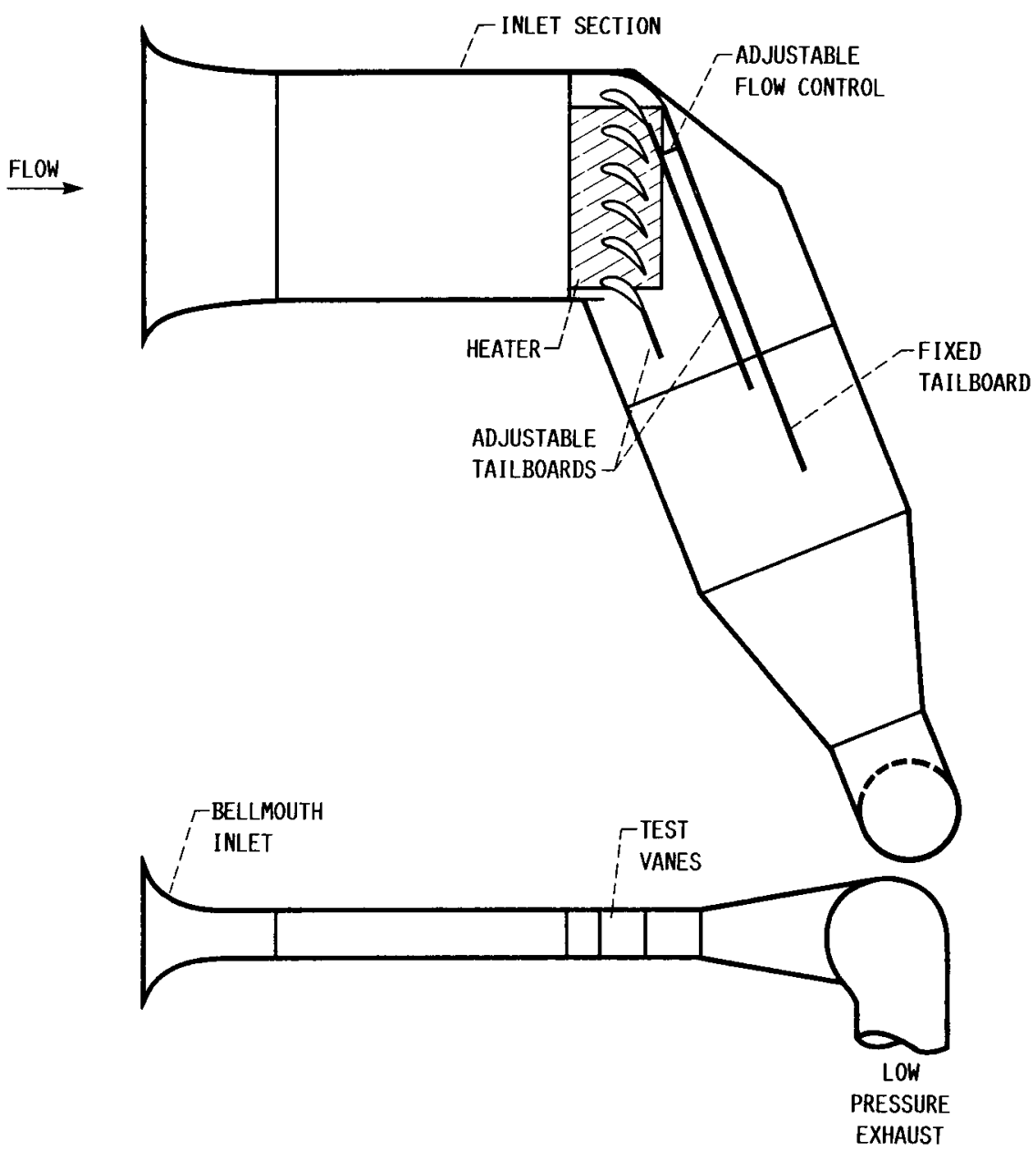

FIGURE 1. - TEST FACILITY.

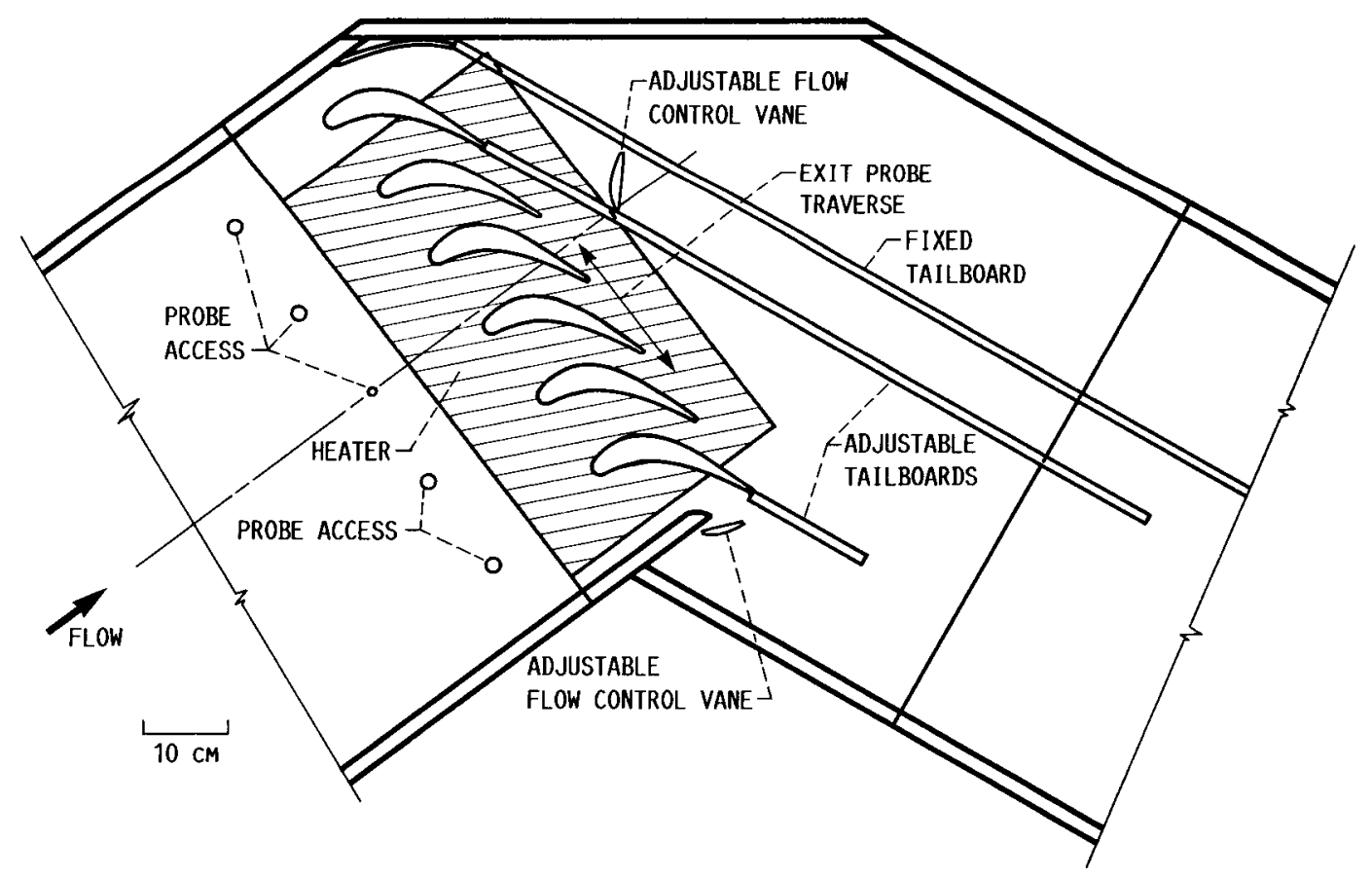

FIGURE 2, - ENDWALL HEAT TRANSFER TEST CONFIGURATION. 


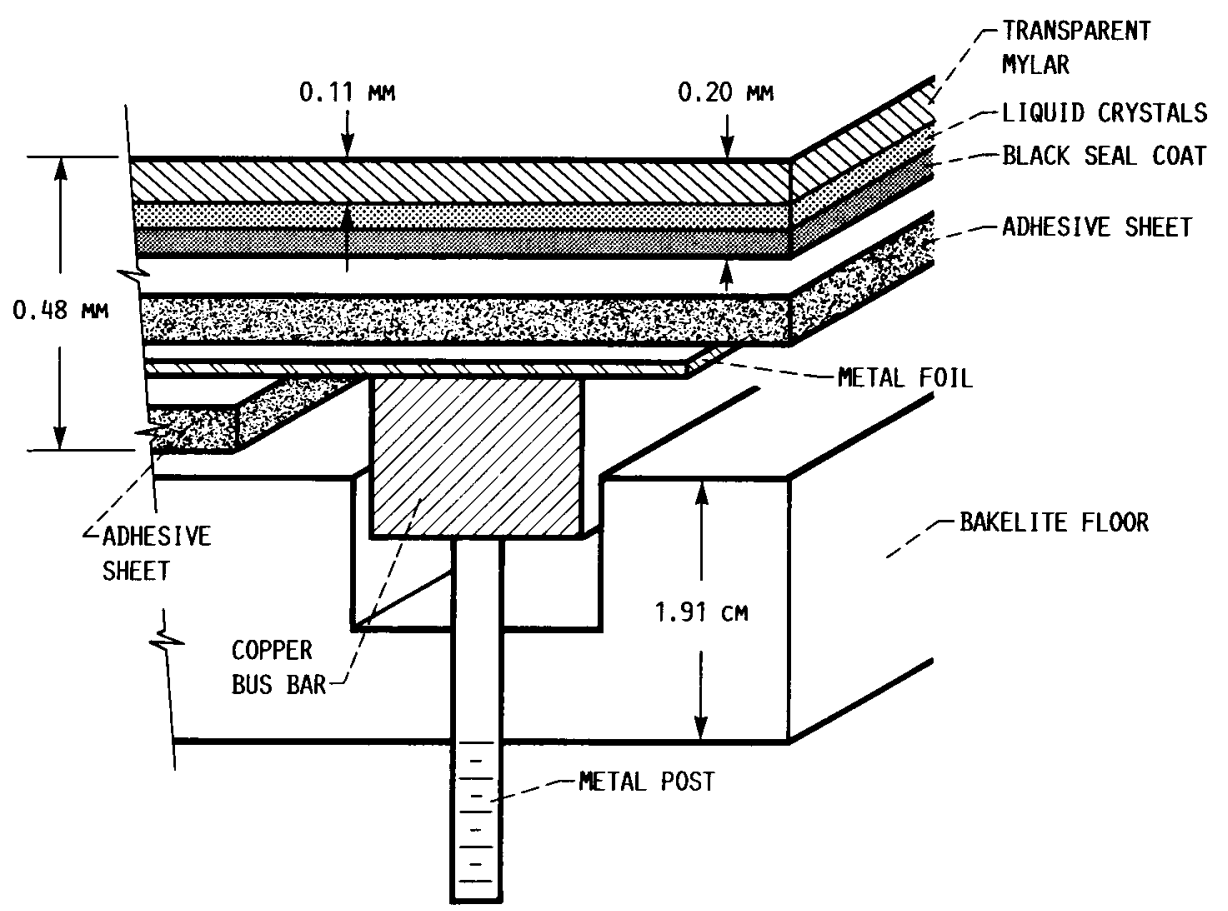

FIGURE 3. - HEATER AND LIQUID CRYSTAL SHEET ASSEMBLY.

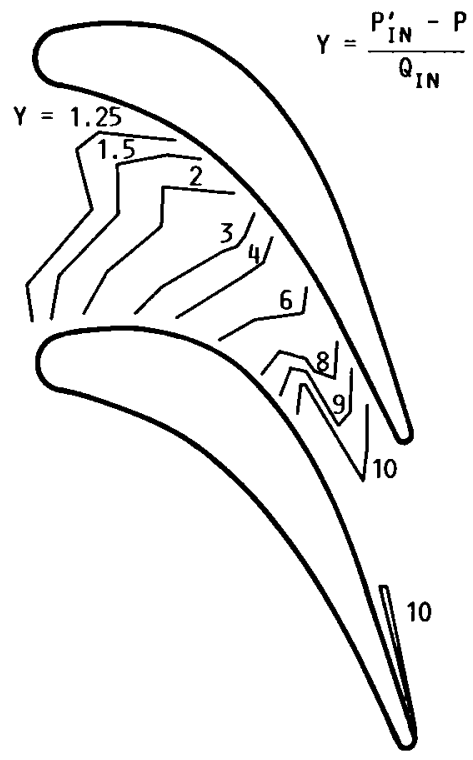

FIGURE 4. - ENDWALL PRESSURE COEFFICIENTS. 


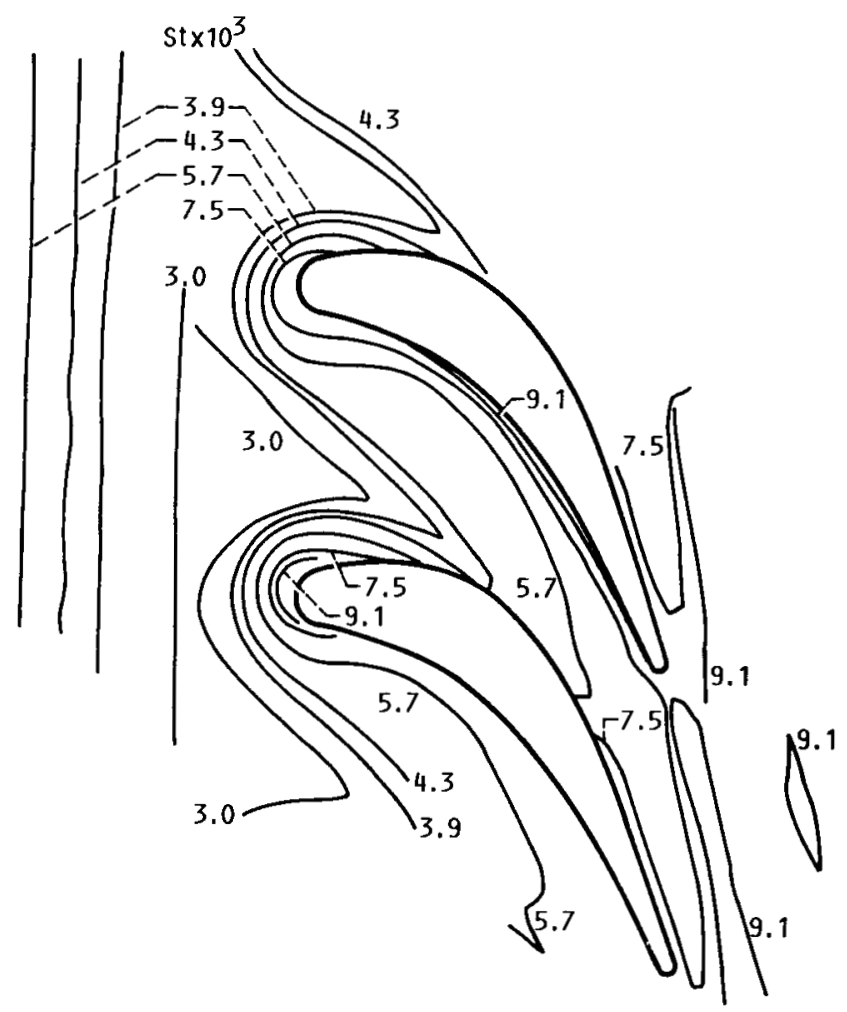

(a) $\mathrm{Re}_{1}=72900$.

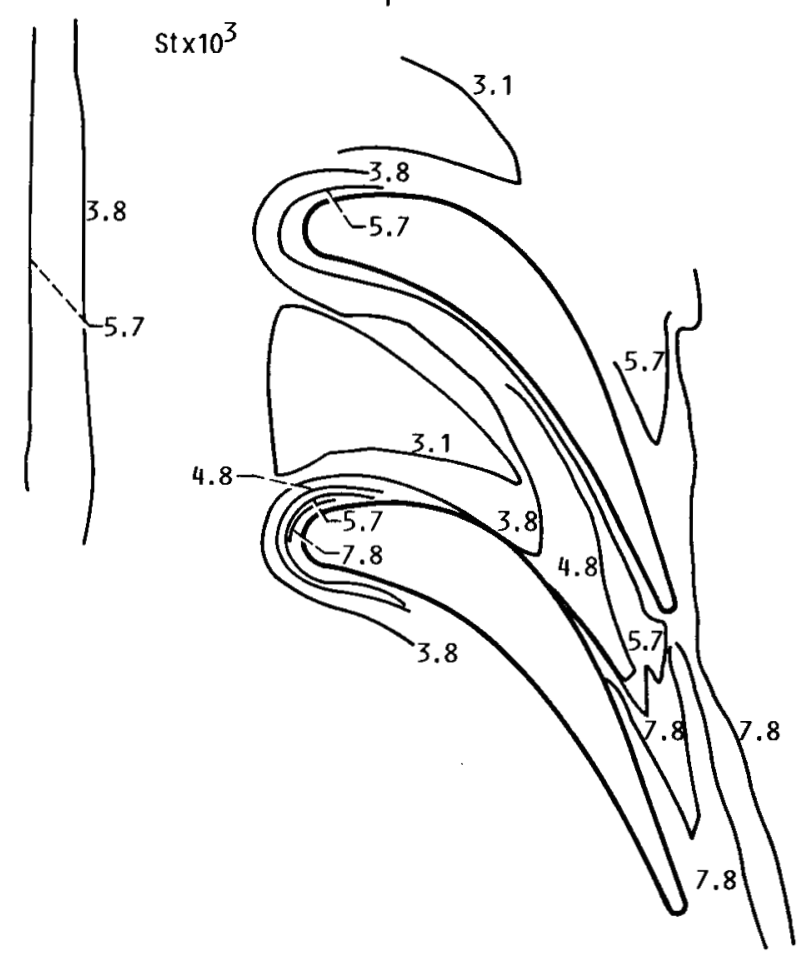

(b) $R e_{1}=137000$.

FIGURE 5. - ENDWALL STANTON NUMBER CONTOURS WITH NO INLET SECTION.

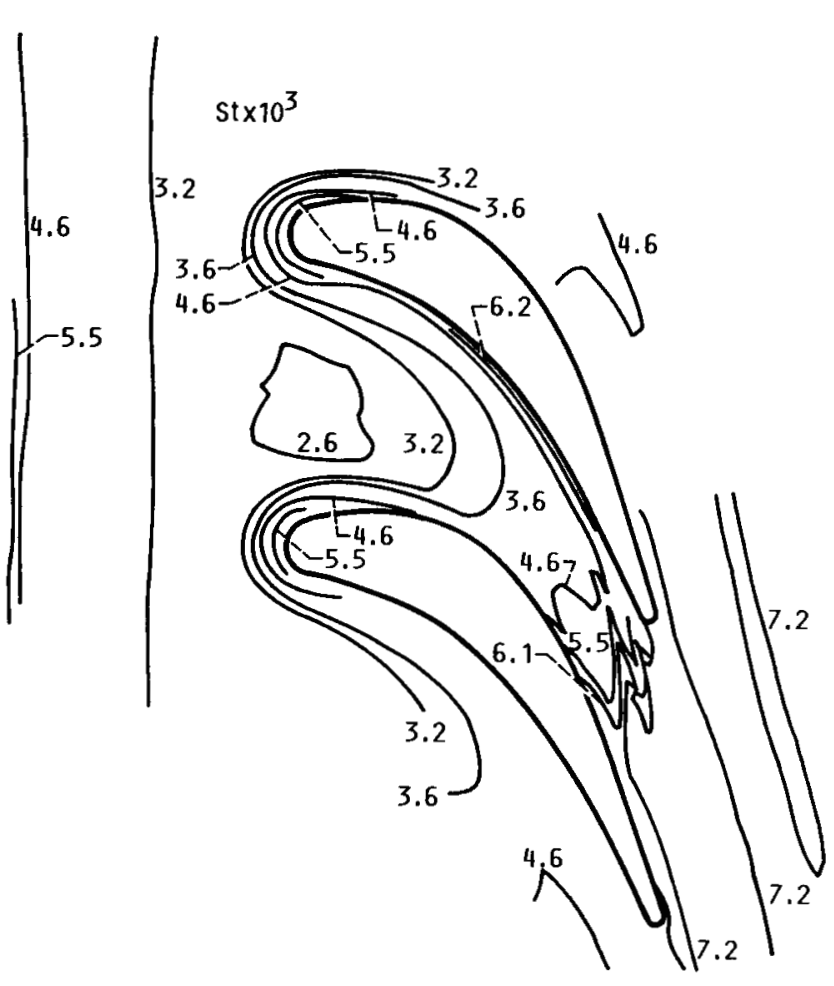

(c) $\mathrm{Re}_{1}=272000$.

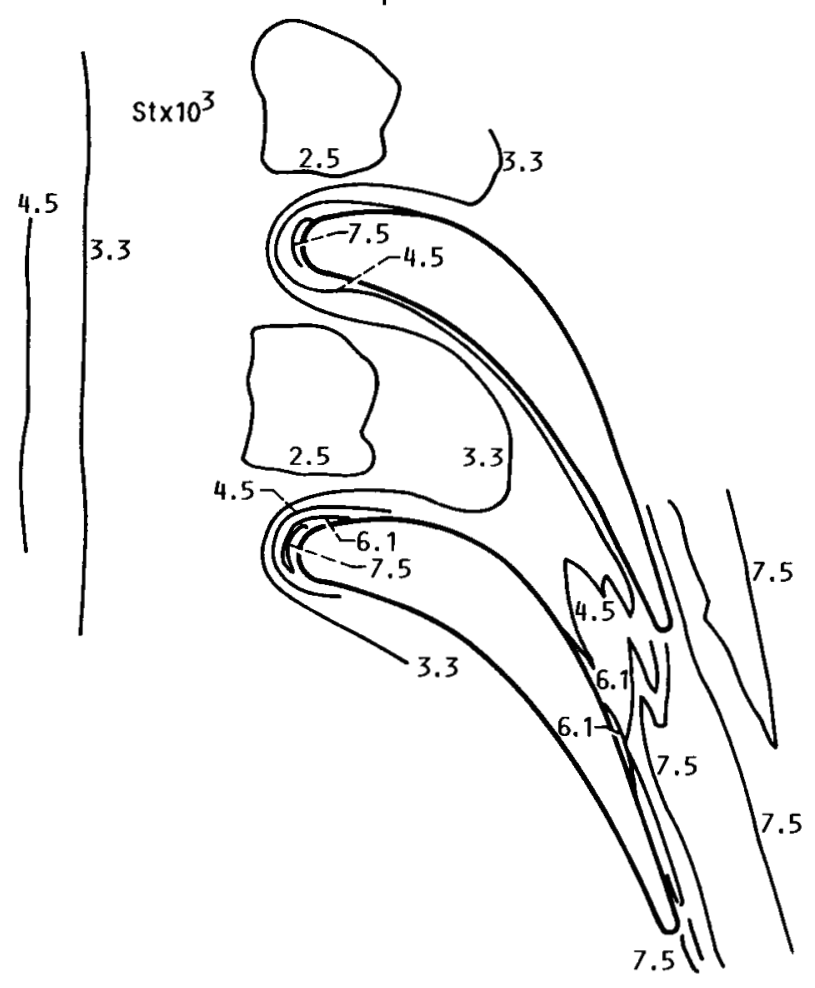

(d) $R e_{1}=395000$.

FIGIJRE 5. - CONCLUDED. 


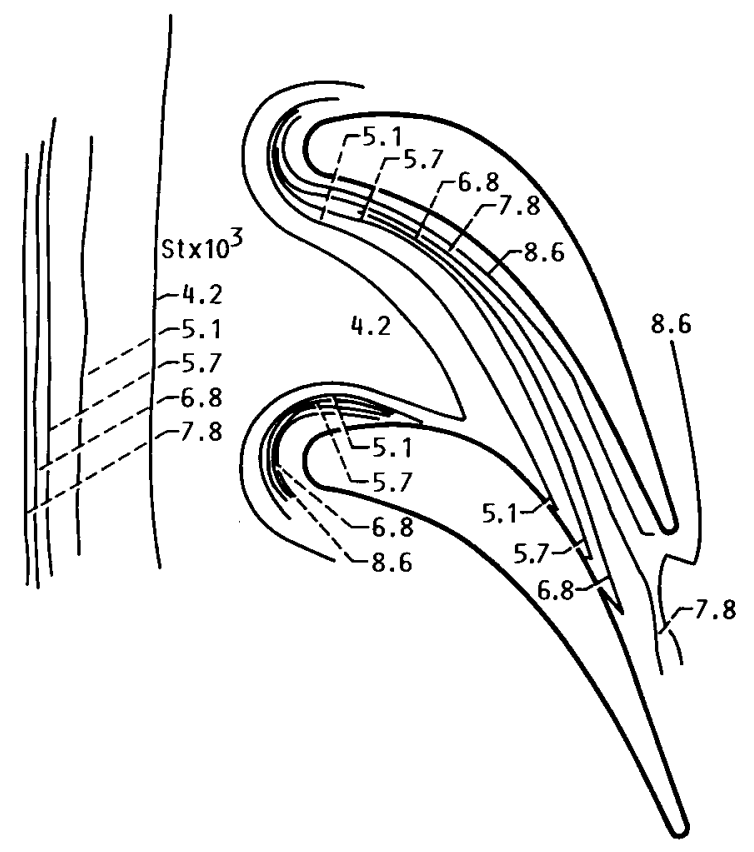

(a) $\mathrm{Re}_{1}=77000$.

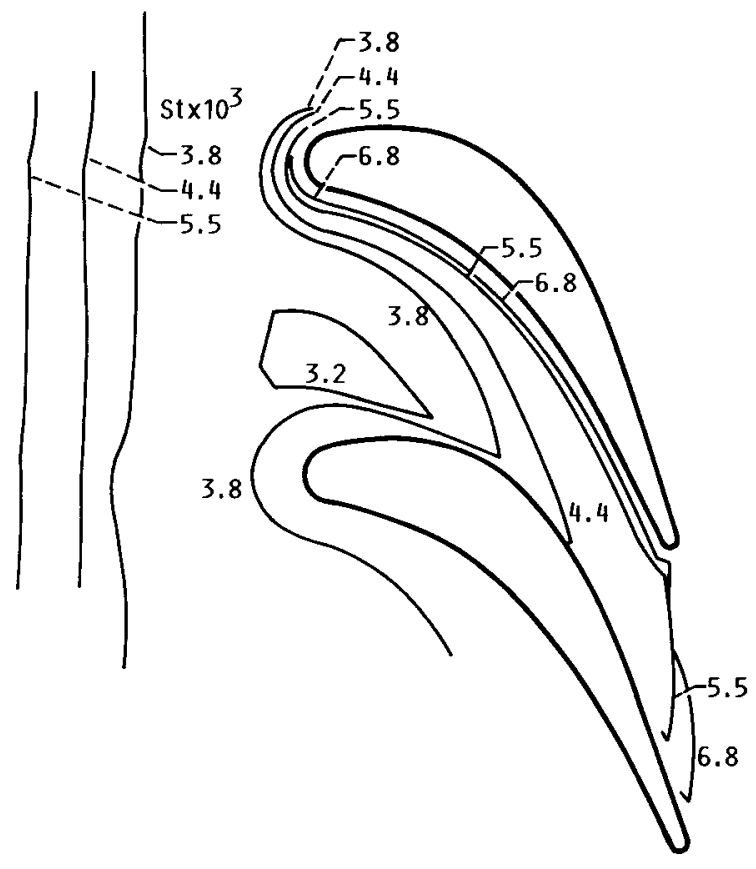

(b) $\mathrm{Re}_{1}=147000$.

FIGURE 6. - ENDWALL STANTON NUMBER CONTOURS WITH SHORT INLET.

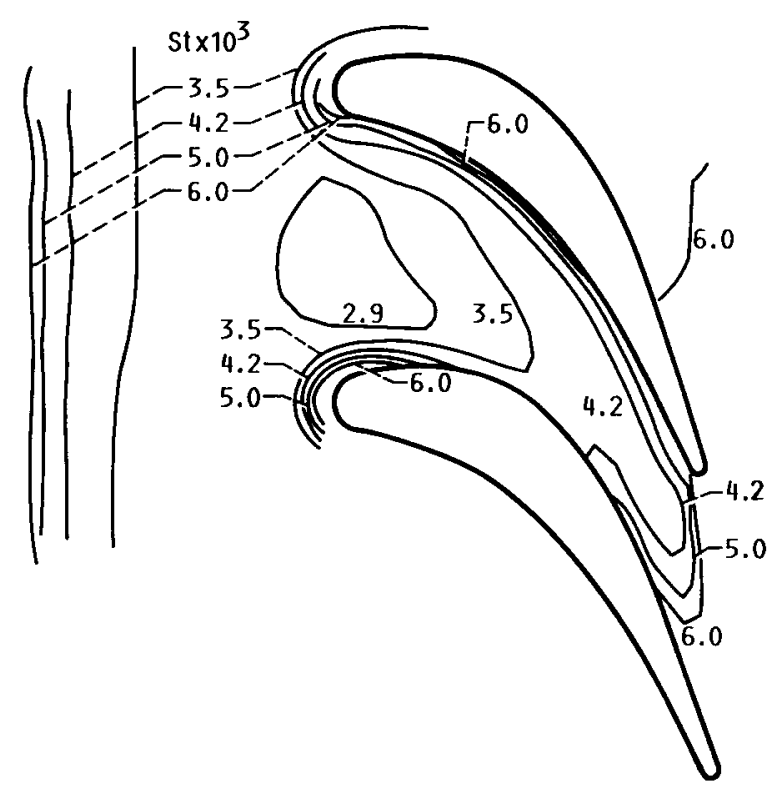

(c) $\mathrm{Re}_{1}=266000$.

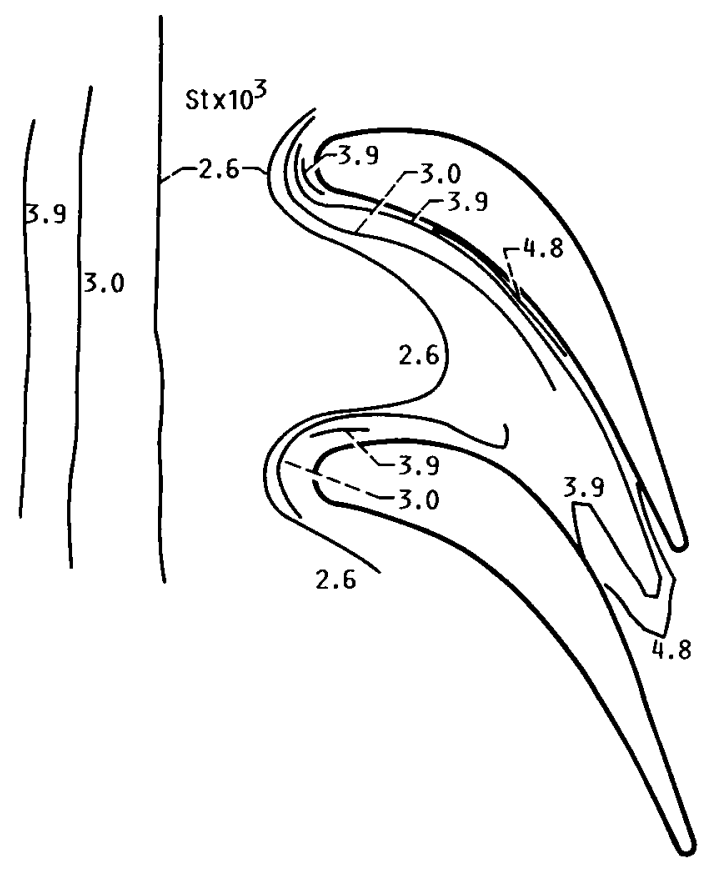

(d) $R e_{1}=420000$.

FIGURE 6. - CONTINUED. 


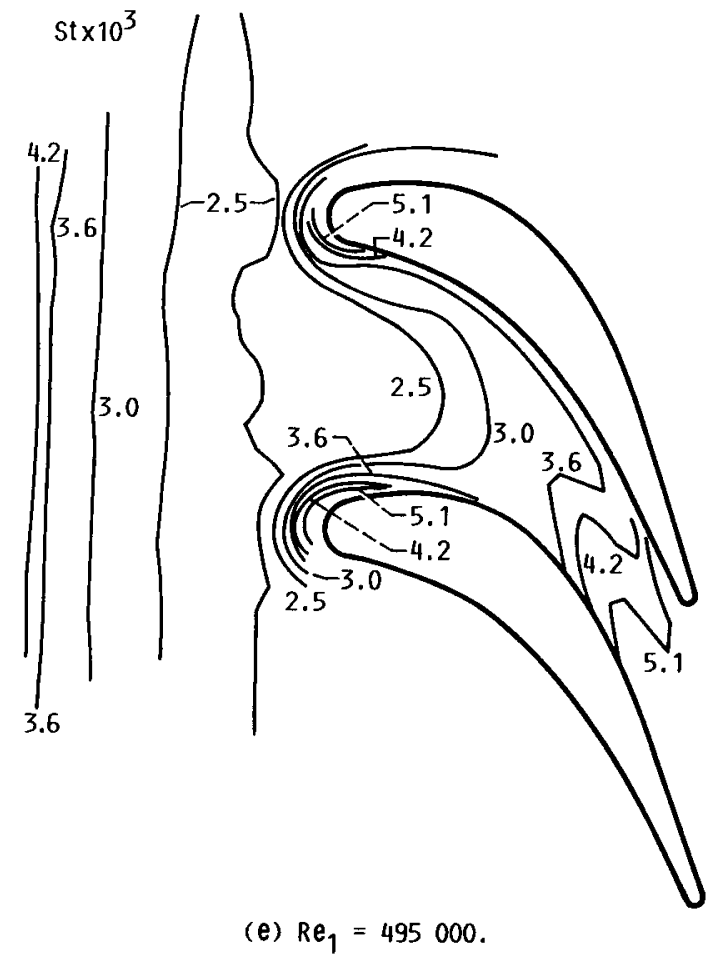

FIGURE 6. - CONCLUDED.

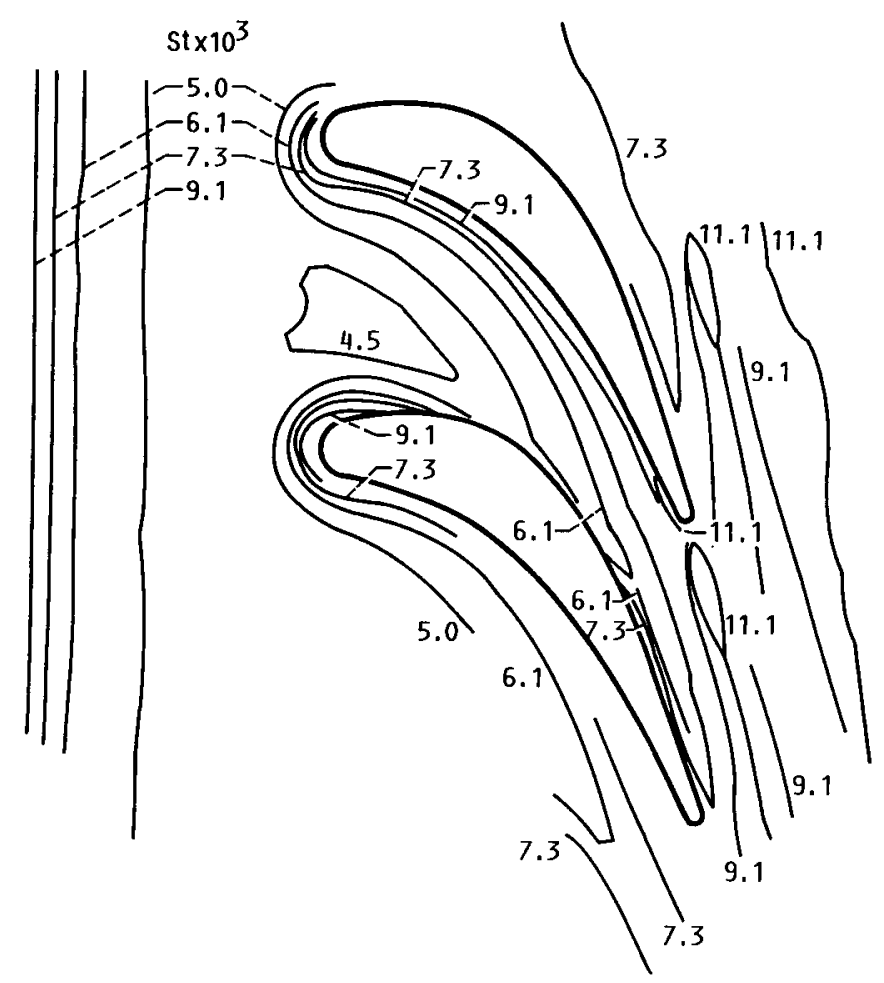

(a) $\mathrm{Re}_{1}=78000$.

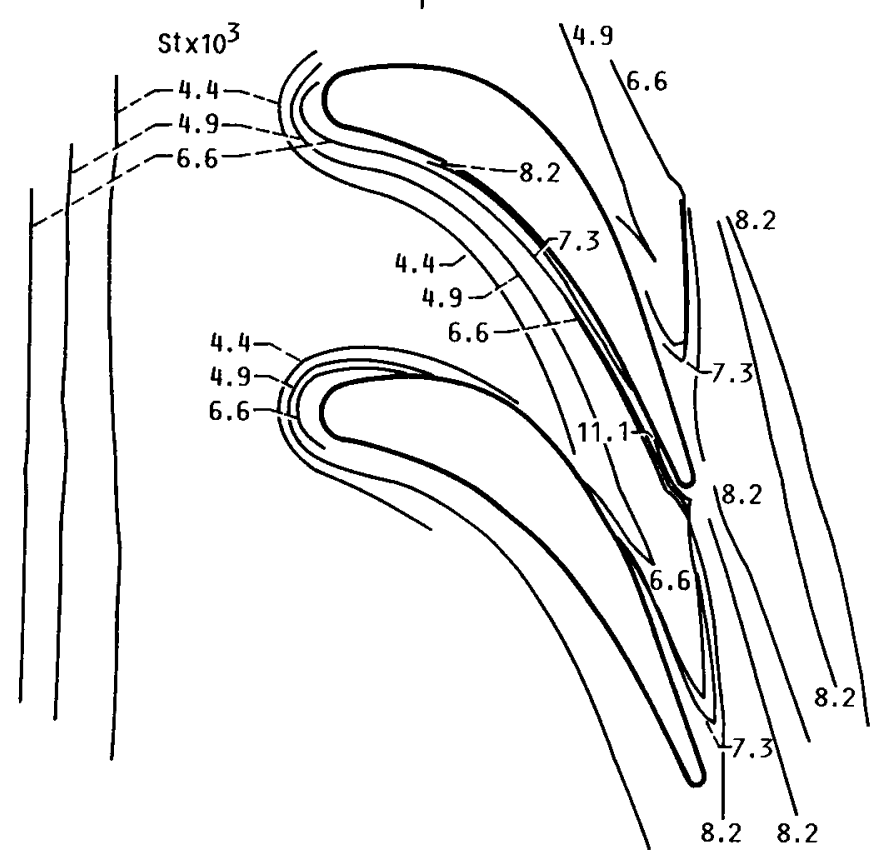

(b) $R e_{1}=160000$.

FIGURE 7. - ENDWALL STANTON NUMBER CONTOURS WITH LONG INLET. 

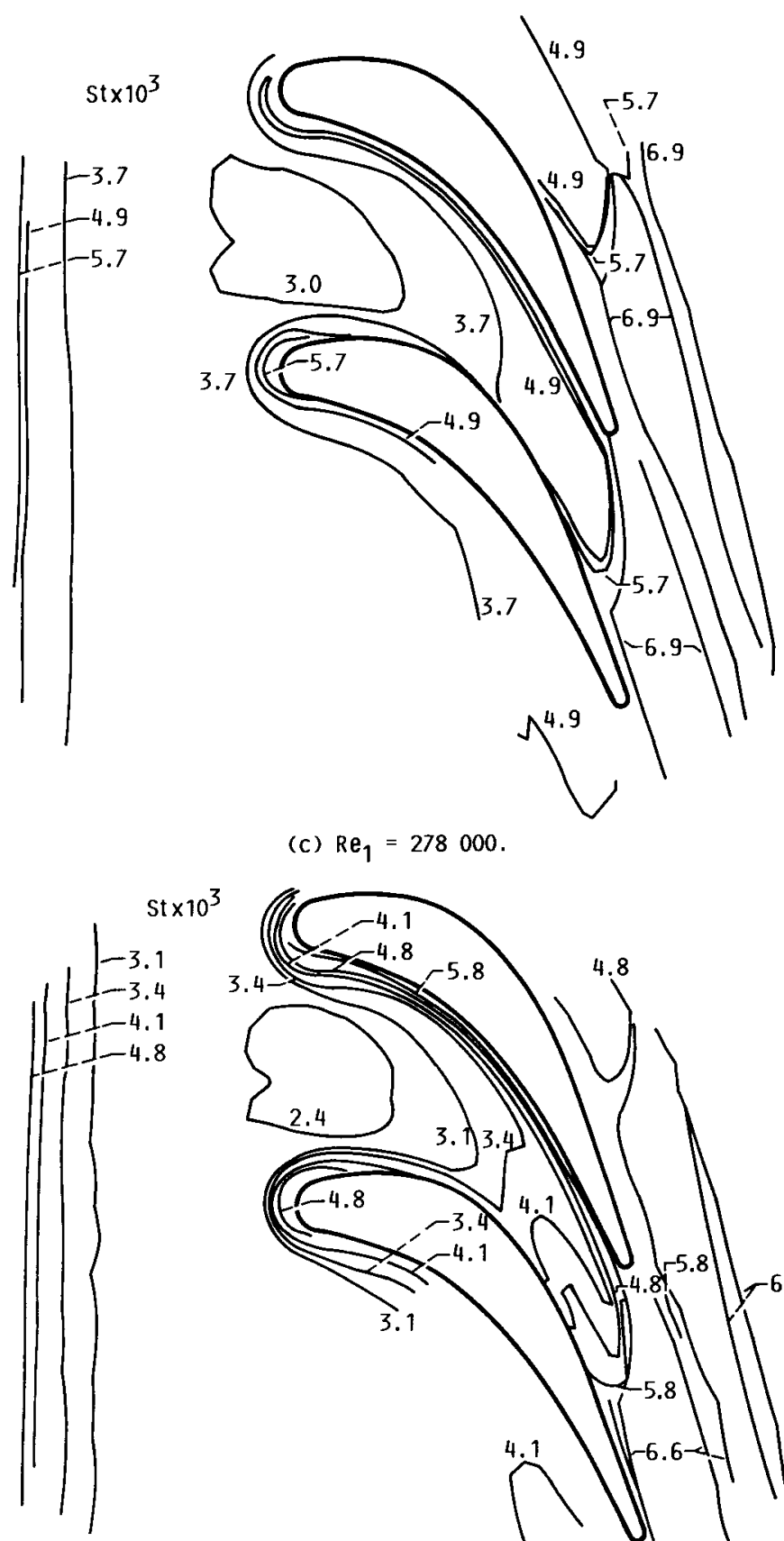

(c) $R e_{1}=278000$.
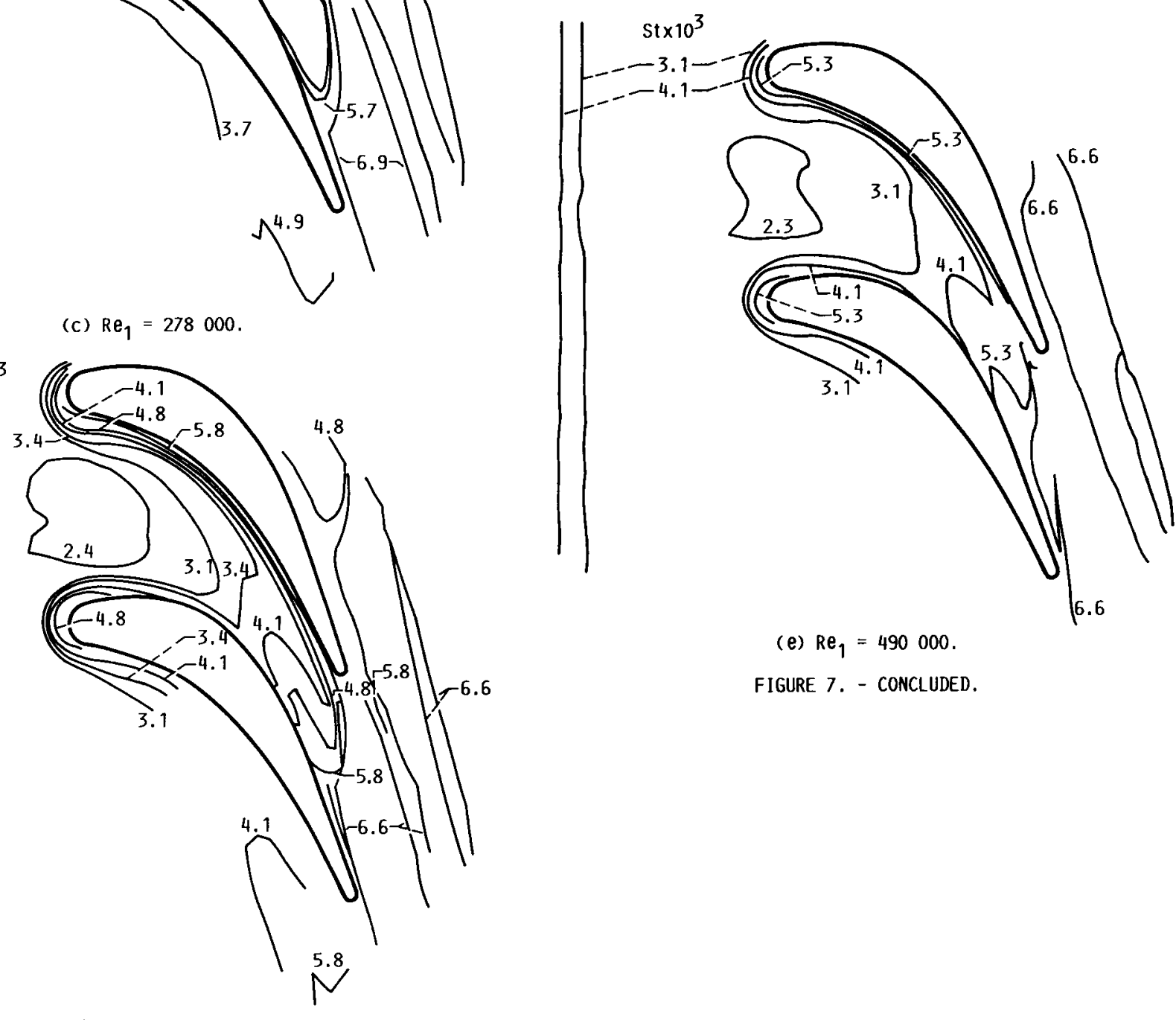

(e) $R_{1}=490000$.

FIGURE 7. - CONCLUDED.

(d) $\mathrm{Re}_{1}=390000$.

FIGURE 7. - CONTINUED. 

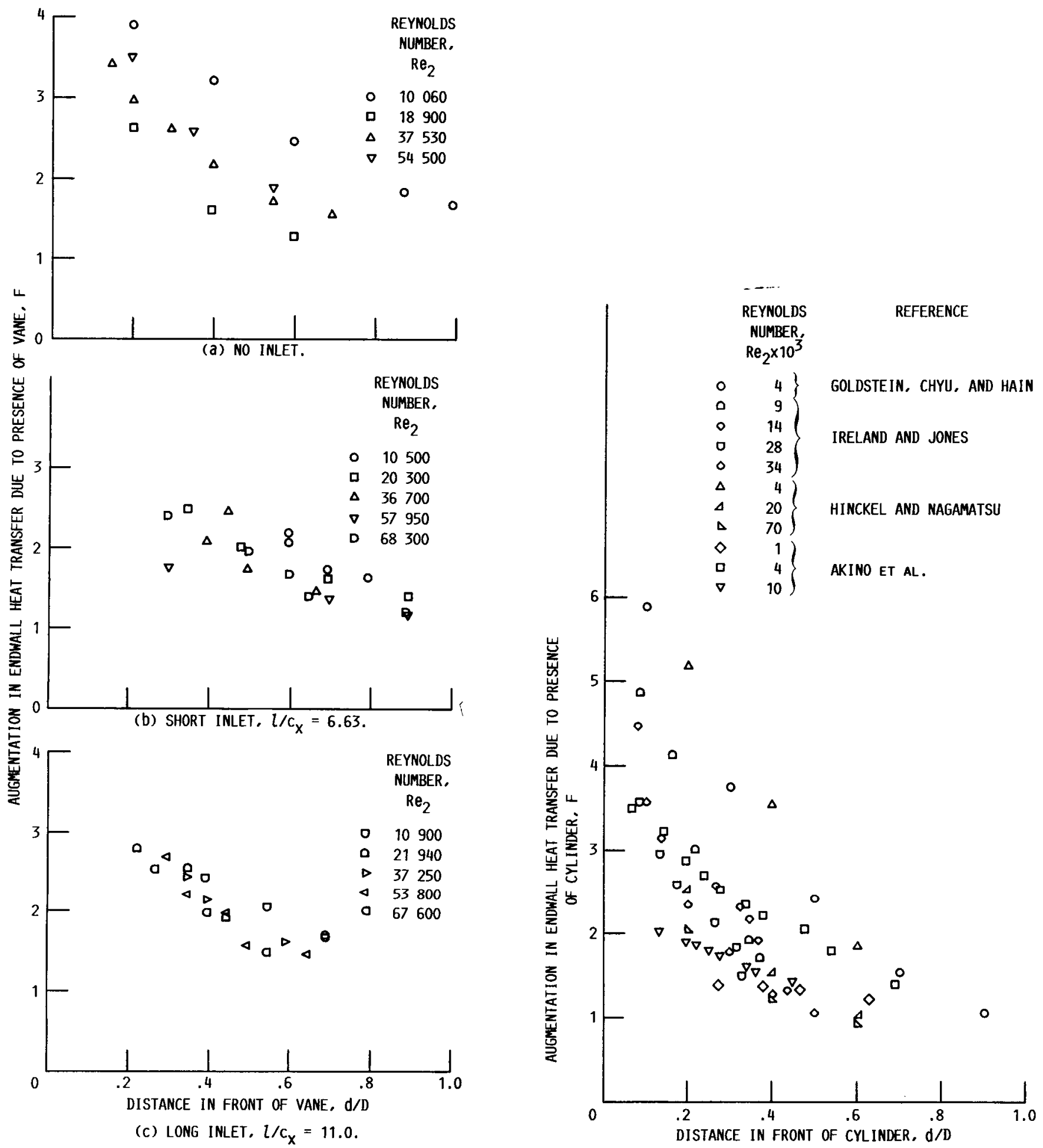

FIGURE 8. - HEAT TRANSFER AUGMENTATION IN LEADING EDGE REGION.

FIGURE 9. - ENDWALL HEAT TRANSFER AUGMENTATION DUE TO PRESENCE OF CYLINDER. PREVIOUS INVESTIGATIONS. 


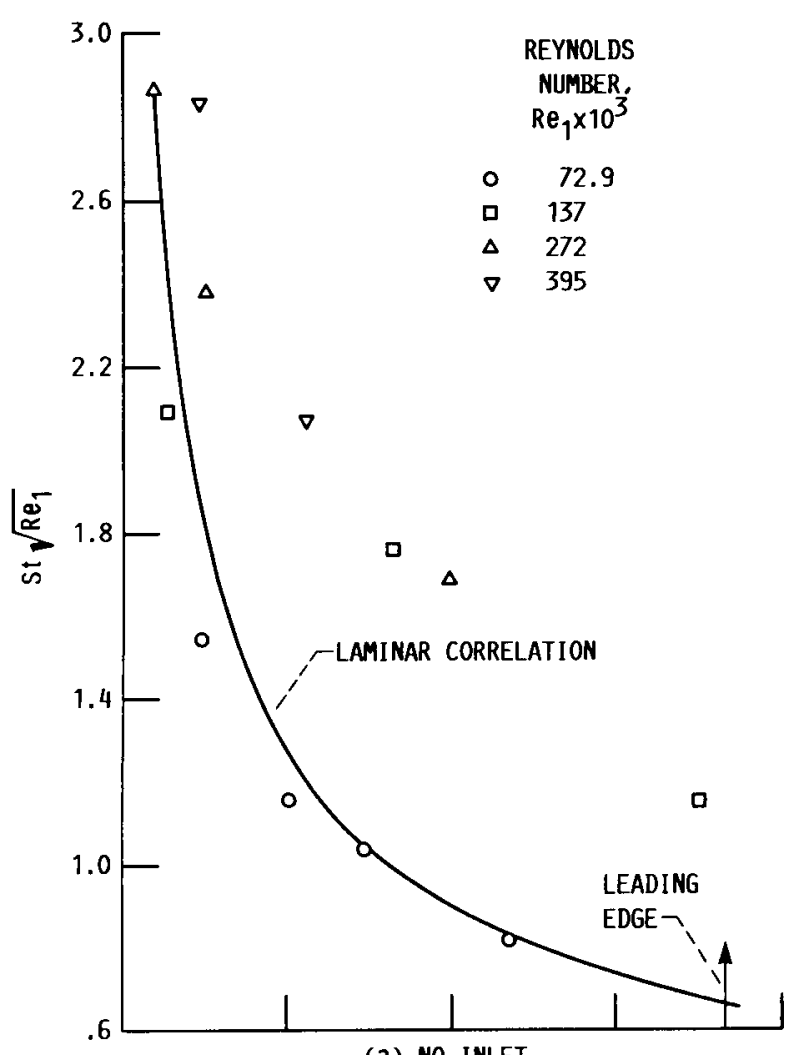

(a) NO INLET.

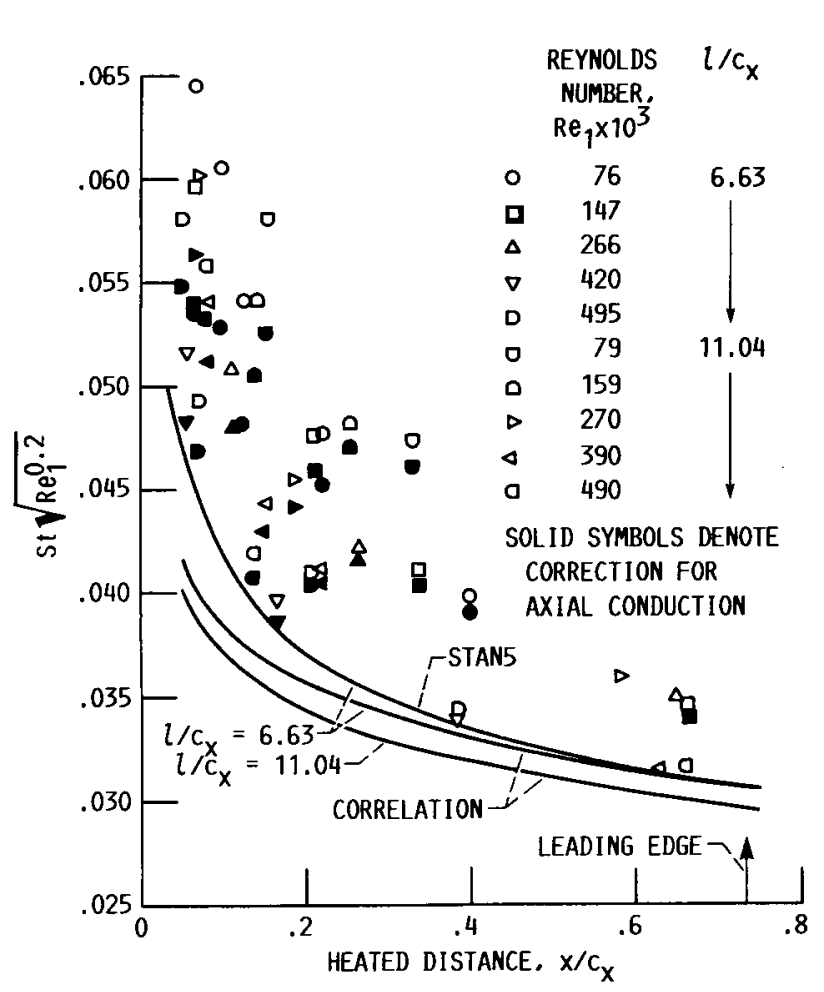

(b) SHORT AND LONG INLETS.

FIGURE 10. - ENDWALL HEAT TRANSFER UPSTREAM OF THE VANES.

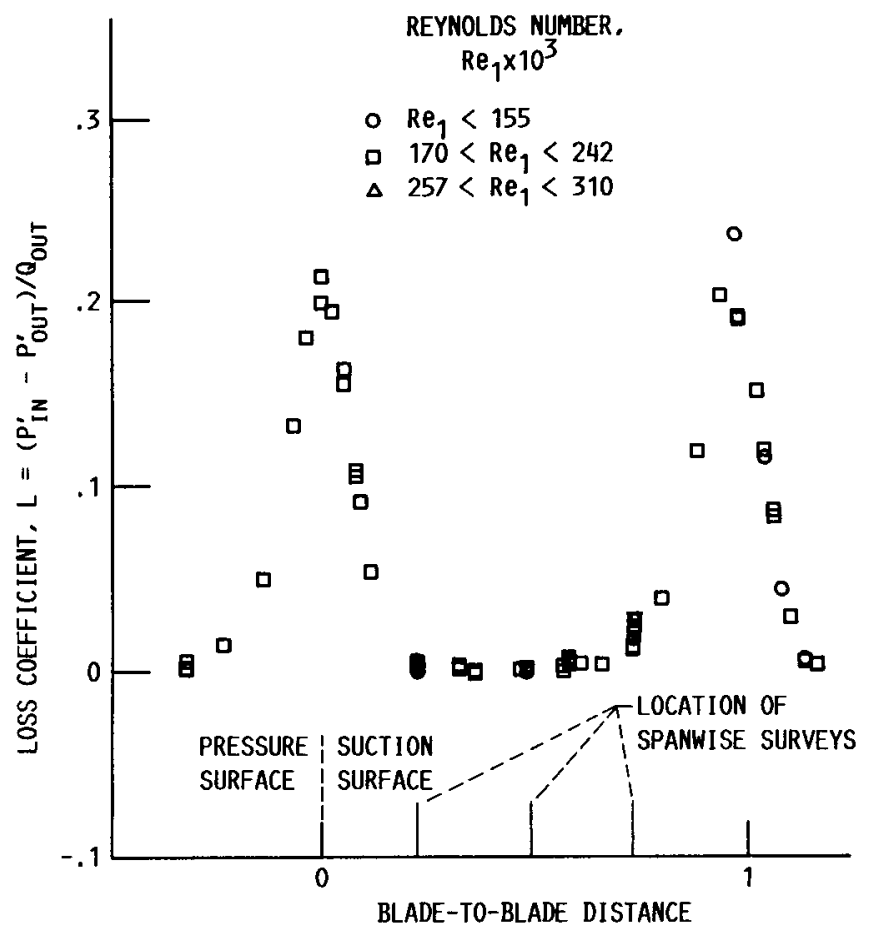

FIGURE 11. - PRESSURE LOSS COEFFICIENT AT MIDSPAN. 


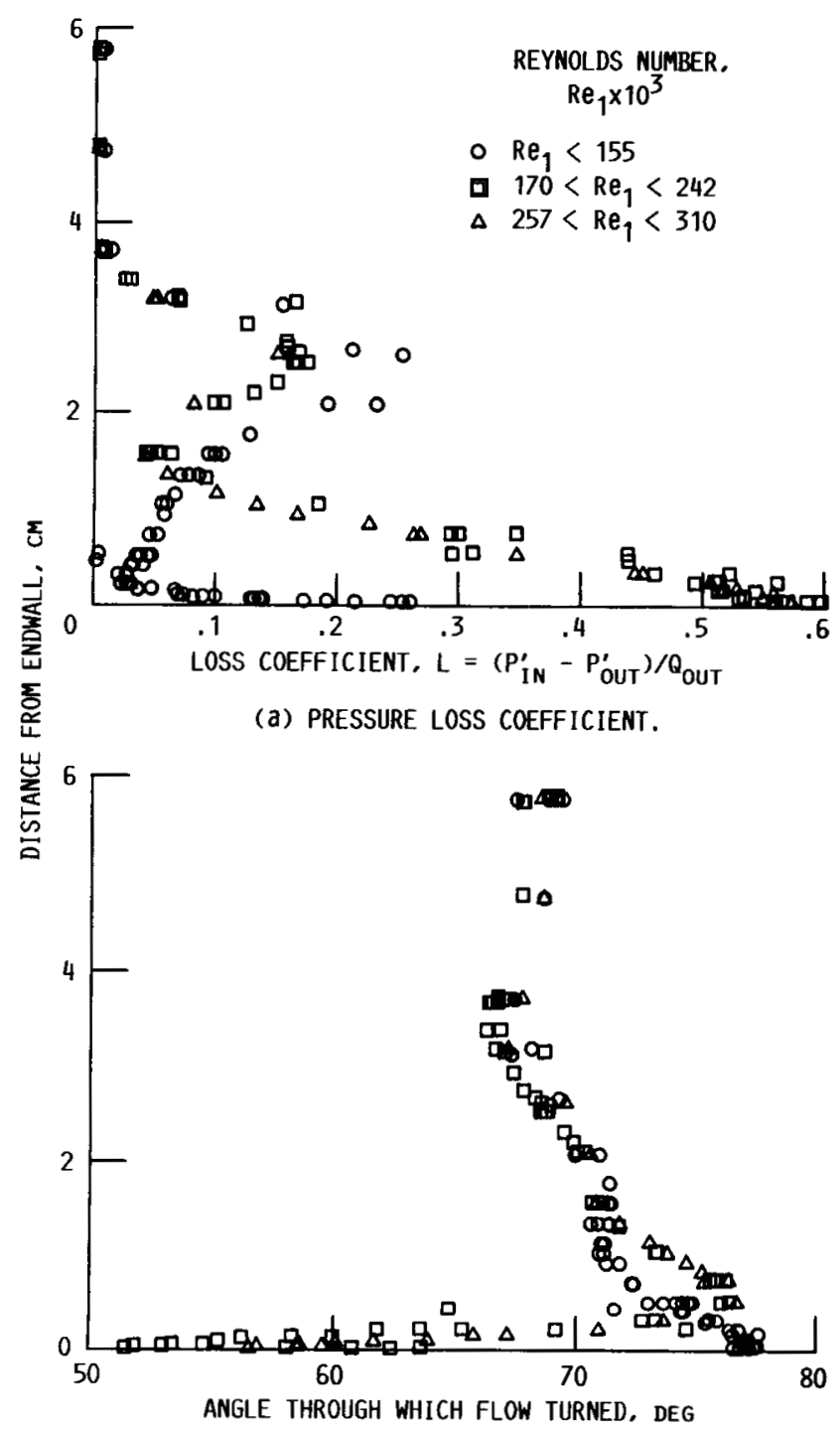

(b) FLOW ANGLE.

FIGURE 12. - SPANWISE SURVEY RESULTS NEAR SUCTION SURFACE.

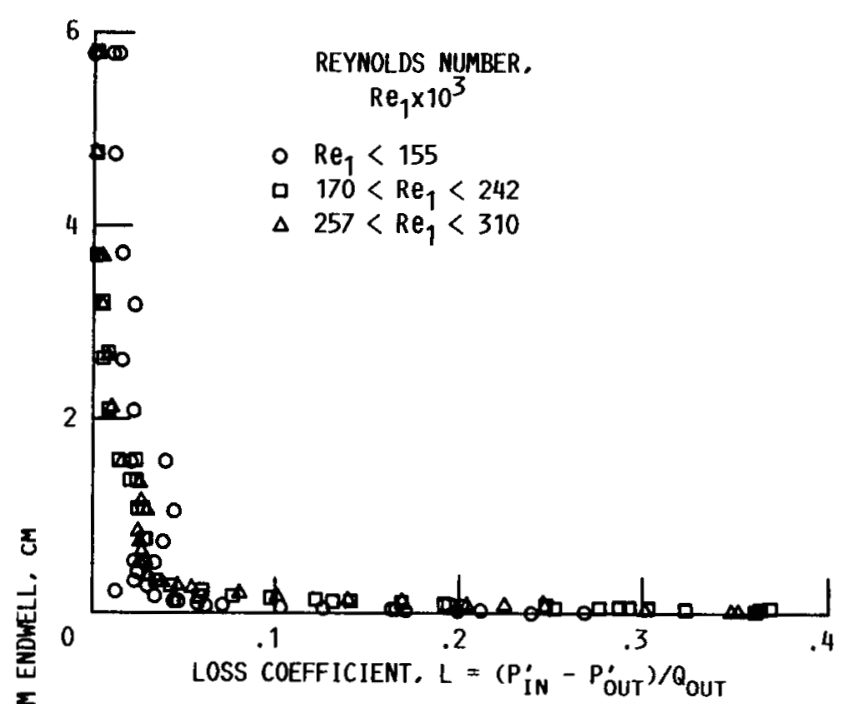

(a) PRESSURE LOSS COEFFICIENT.

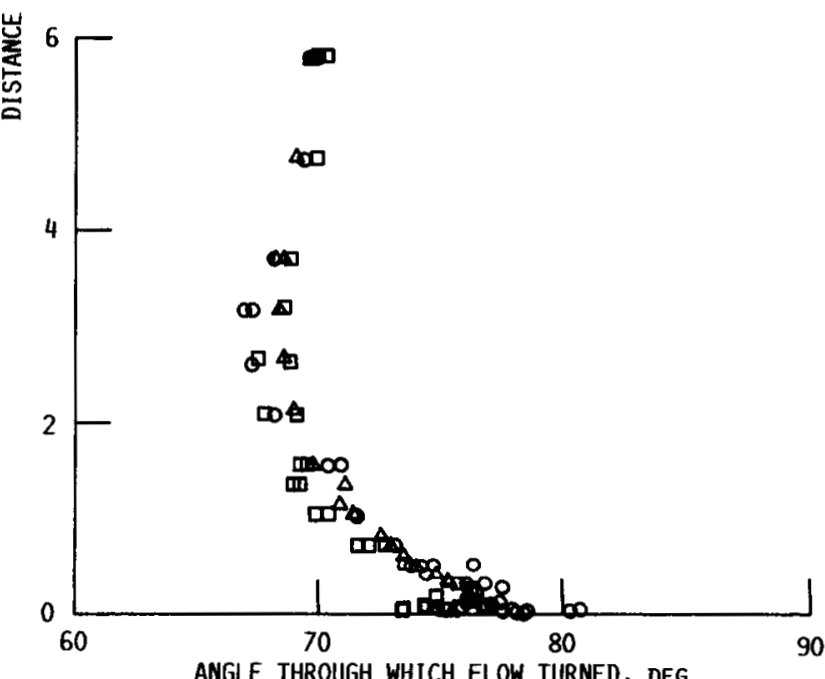

(b) FLOW ANGLE.

FIGURE 13. - SPANWISE SURVEY RESULTS MIDWAY BETWEEN VANES. 


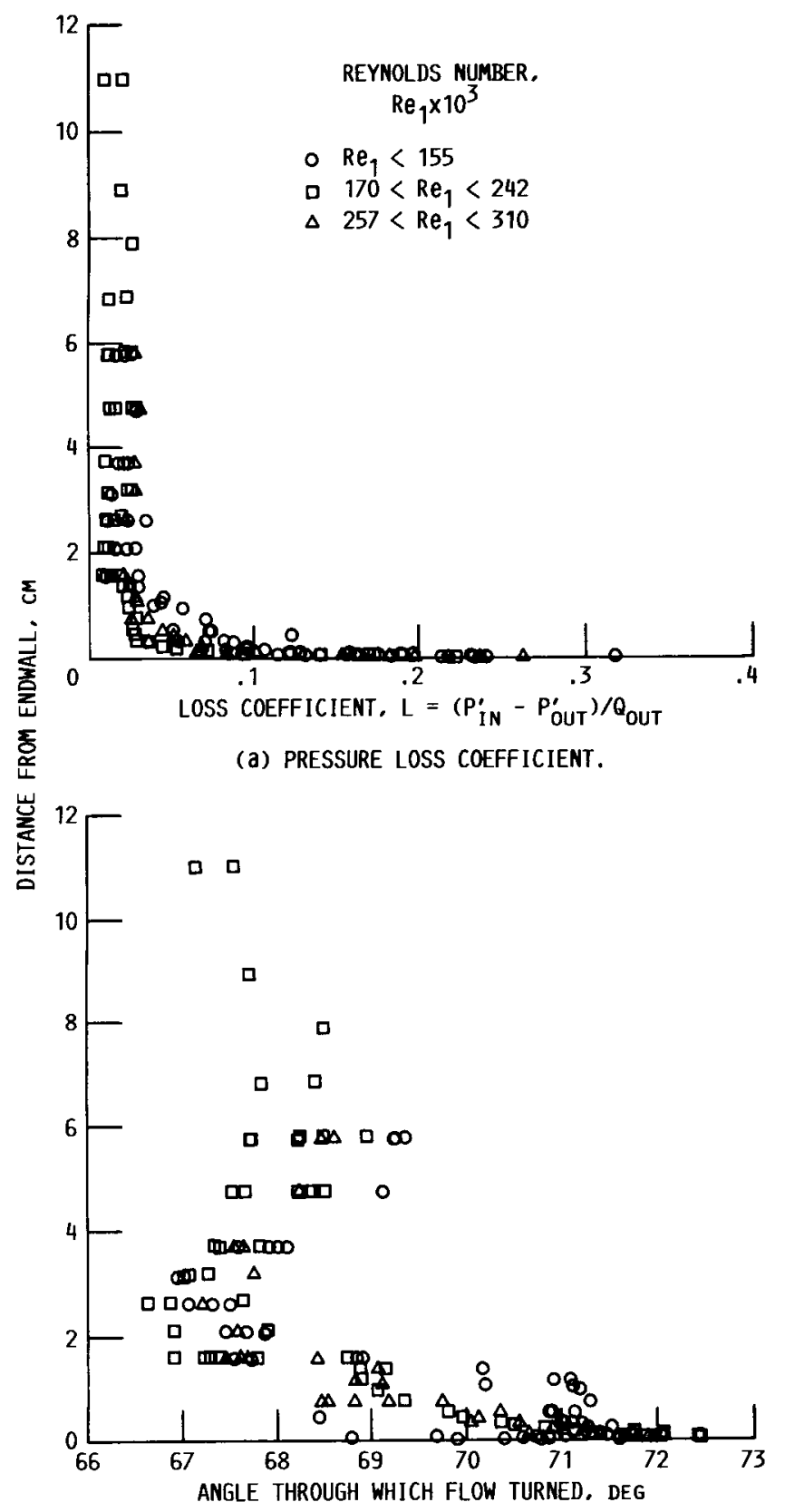

(b) FLOW ANGLE.

FIGURE 14. - SPANWISE SURVEY RESULTS NEAR PRESSURE SURFACE.

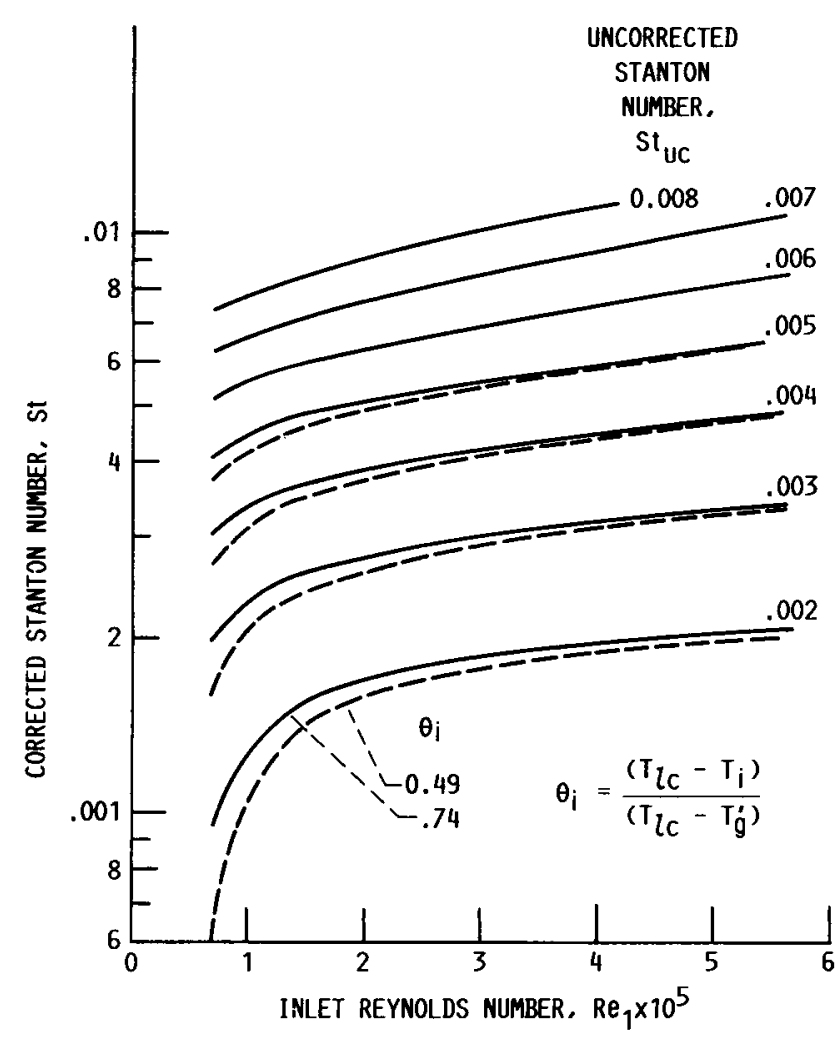

FIGURE A1. - COMPARISON OF CORRECTED AND UNCORRECTED STANTON NUMBERS FOR TEST CONFIGURATION. 


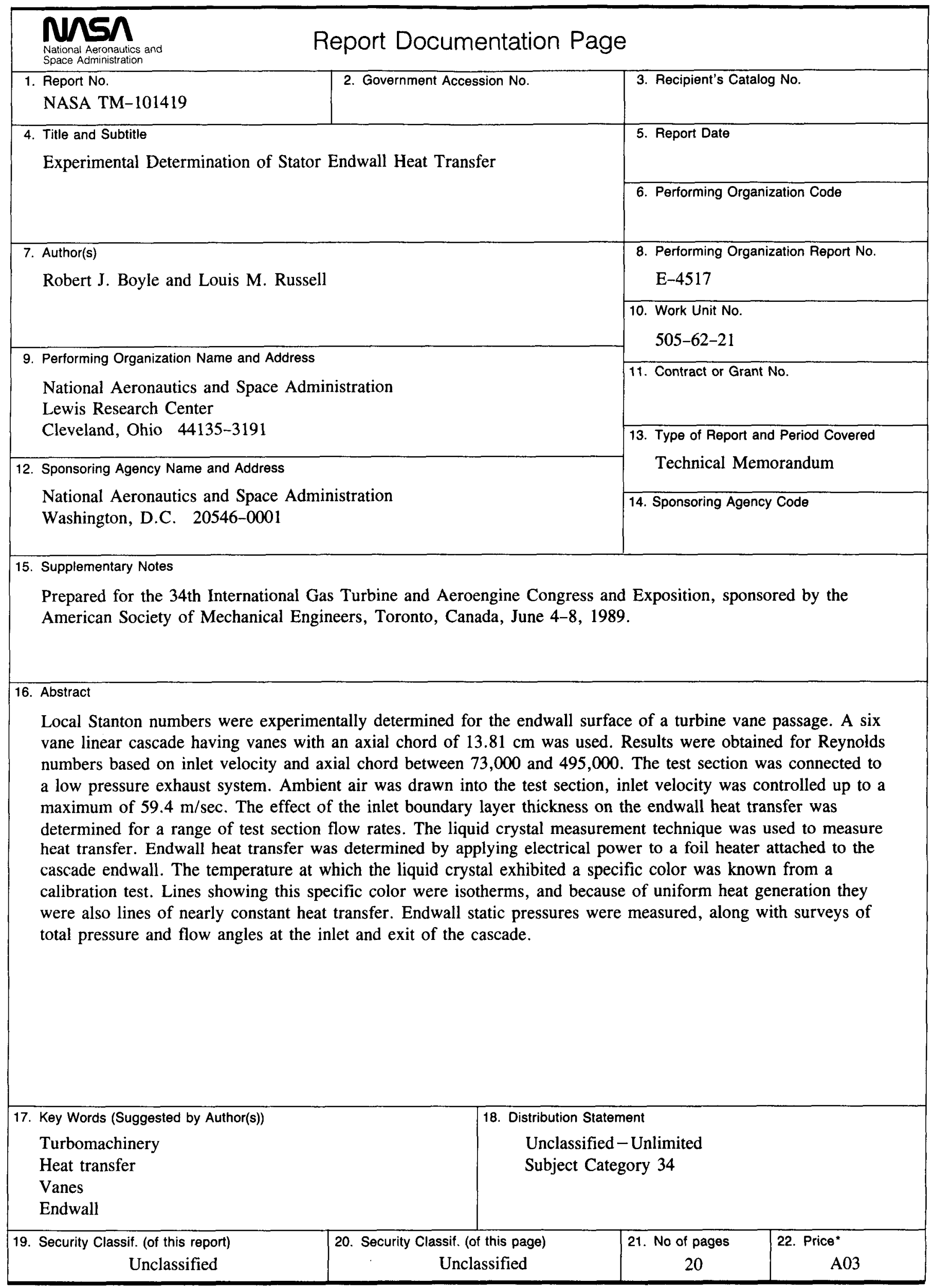

